IFN Working Paper No. 758, 2008

\title{
Colonial Heritage and Economic Development
} Andrea Asoni 


\title{
Colonial Heritage and Economic Development
}

\author{
Andrea Asoni* \\ University of Chicago and the Research Institute of Industrial Economics (IFN)
}

August 4, 2008

\begin{abstract}
While the importance of institutions for explaining cross-country income differences is widely recognized, comparatively little is known about the origins of economic institutions. One strand of the literature emphasizes cultural differences while another points at exogenous environmental factors such as mortality and climate. Both are supported by some empirical evidence. I reconcile the two schools of institutional origins by proposing a theory of self-selection of colonists to different geographic destinations. Exogenous characteristics such as climate, mortality and factor differences determine which type of settler decides to move to a particular colony. Settler type, in turn, shapes the institutional quality of the new country. The model is used to confirm observed regularities reported by previous researchers. Furthermore, robust new evidence is presented in support of this selection process. The results suggest that any theory of colonial development that does not take selection into account will be incomplete.
\end{abstract}

Key words: Economic Development; Culture; Origins of political institutions.

JEL classification: O11; O12; N10; P16.

*I would like to thank Nancy Stokey, Casey Mulligan, Tino Sanandaji, Gideon Magnus, David Cesarini, Magnus Henrekson and participants in the Macro Working Group at University of Chicago for useful comments. All remaining errors are mine. Please send any comments to asoni@uchicago.edu 


\section{Theories of Institutions}

Institutions are arguably the key factor behind economic development, more important than geographical location or trade, for example (North 1990, Acemoglu et al. 2001, Hall and Jones 1999, Rodrik et al. 2004). However, despite their significance having been recognized, there is little consensus about the origin of economic institutions.

Various explanations have been put forth regarding the origins of wealth inducing institutions. Institutions can be the result of the norms and accepted rules of behavior. Alternatively, differences in institutional outcomes among countries might be derived from political struggles over the distribution of resources. Variations in institutions can be seen as evolving from values and shared principles or could, in contrast, be the result of an "engineering process" trying to achieve goals such as efficiency or wealth and power for dominant groups. Alternative explanations are more or less suited to capture different historical circumstances, and different institutional shaping mechanisms can, of course, act at the same time. The problem of the origins of institutions is not only interesting in itself, it is also relevant for the literature that studies economic growth and institutions. Competing institutional theories can explain the same empirical patterns, thereby making identification difficult. Moreover, the lack of an elaborate theory of institutions might lead to a misinterpretation of the data.

This paper will distinguish between two schools of thought on institutional origins, particularly in the case of divergent paths in colonized countries. One school points at the role of what can broadly be defined as culture in explaining cross-country differences in institutional set-ups. Hall and Jones (1999) use the extent of European influence as an instrument for institutions. La Porta et al. (1998) study the legal system and its impact on a series of economic outcomes.

Acemoglu, Johnson and Robinson (2001, 2002) propose an alternative theory of institutional development. They argue that exogenous characteristics, such as settler mortality or population density, determined the type of institutions that were established by the Europeans. In territories favorable to long-term settlement, the Europeans created institutions favoring property rights and contracts enforcement. In places where sizable rents could be exploited or long-term settlement was very costly, the elites instead instituted extractive institutions. The latter type of institutions proved less conductive to long-term economic development. Acemoglu et al.'s theory is appealing and has considerable explanatory power. Glaeser et al. (2004) question some aspects of this theory and the importance of institutions themselves. Human capital might be more important than settlers' mortality in explaining economic growth. They also point out how low mortality is associated with a high level of human capital and call for a more comprehensive approach.

So far, the literature has identified various empirical regularities: the association between settlers' mortality and economic growth (Acemoglu et al., 2001); the importance of human capital and the correlation 
between human capital and early mortality (Glaeser et al., 2004) and the relationship between European influence and development (Hall and Jones, 1999). The latter does not examines possibile differences among Europeans. I suggest a theory of colonial institutions that reconciles these empirical patterns and is supported by new evidence. Institutions are strongly related to individual and social norms. Institutions, especially informal ones, are embedded in human preferences and cognitive models. Each person has a set of beliefs on how to behave in a society and what to expect from other people. These principles and values strongly influence formal institutions. In the case of colonial institutions, the norms and values of the first settlers, i.e. the institutions-setting colonists, are very important.

I propose a theory of self-selection of settlers. People are heterogeneous in their preferences over institutions; for example, some emphasize individual responsibility and self-reliance, others believe in solidarity and the importance of a superior authority. Distinct settlers went to different territories and variation in their preferences over institutions (culture) explains cross-country institutional differences. Mortality and other exogenous geographical characteristics determined the type of colonists that would settle in any given territory. Each type of settler then established institutions that reflected its preferences.

Once established, these institutions influenced the economic fortunes of the colonies. I present robust empirical evidence in support of this hypothesis. There are clear patterns in the data that associate certain cultural types (British, Protestant, Common Law countries) with low mortality territories. The theory proposed in this article explains why British/Protestant territories are those with better institutions and better economic outcomes, both now and in colonial times, why low mortality is associated with better economic outcomes, why high human capital is associated with low mortality and why European influence is associated with better outcomes and low mortality. I argue that there are underlying cultural factors, only partially captured by our measures of institutions and culture, that are driving all these results.

Moreover, this theory does not only explain the origins of colonial institutions but also their persistence, something that was left unexplained by Acemoglu et al. (2001): institutions are part of the cultural heritage of a nation, hence they are transmitted from one generation to the next, especially when successful.

Before presenting the theory and the empirical evidence in more detail, previous literature will be discussed in the next section. Section three illustrates the model guiding the analysis of the data and section four will discuss the data and the empirical strategy. The fifth section will show the results of our investigation and section six will conclude the paper.

\section{Institutions and Growth}

There is a vast literature that studies the effect of institutions on economic development. A central idea, going back at least to North and Thomas (1973), is that good institutions, particularly those protecting property rights, stimulate economic growth by aligning individual and societal welfare. Individuals are far more likely to engage in productive behavior and accumulate physical or human capital if their investments 
are protected. Over time, economists have used different ways of measuring the degree of property rights protection. This does not only include the existence of formal and informal rules against expropriation. The actual implementation of any given set of rules must also be taken into account. This is why, in addition to the "risk of expropriation", (La Porta et al. 2002) economists used measures such as corruption indicators and the possibility for protection against the violation of individual rights (Mauro 1995). Rule of law is often used as a proxy for institutional quality (Hall and Jones 1999).

Naturally, the choice of the relevant variable depends on the question we wish to investigate. When studying the effect of institutions on the performance of former communist countries, corruption is of particular importance (Sonin 2003, Johnson et al. 2002). In the description of the English Civil War and the Glorious Revolution, measures of rule of law and expropriation risk are of larger interest (North and Weingast 1989). Most of these attempts are criticized on basis of possible endogeneity. Besides obvious measurement problems, different theoretical arguments do not only justify the positive impact of institutions on economic development but also the positive impact of economic growth on institutions. As people become richer they might require more appropriate institutions. It is also possible that good institutions and economic growth are driven by the same underlying factors, such as human capital. In these cases, identifying the causal relationship can be complicated. Economists have tried to overcome these difficulties through the use of instrumental variables. I will briefly describe the most successful instrumental strategies since this paper builds on them.

Hall and Jones (1999) present a model where different "social infrastructure(s)" explain cross-country disparities in productivity. Using a broad definition of institutions that includes government policies in addition to rules, norms and political organization, they obtain the result that better institutions have a positive effect on growth. Their instruments are meant to capture the influence of European culture on the country considered (assuming that European culture had a positive effect on local institutions). Those instruments include geographical distance from the equator, as Europeans were more likely to settle in regions far from the equator, and the percentage of the population speaking a European language as their first language. There is some room for criticizing these instruments. Geography may affect growth through different channels, for example climate and distance (even if more recent articles have found that this effect is, if anything, weak) and the fraction of the population speaking a European language may at least be partially endogenous. Europeans might have tended to go to more successful countries or residents of more successful countries might be more likely to learn European languages.

Acemoglu et al. (2001) define "good institutions" as those protecting private property and reducing the risk of government expropriation. Their theory is that Europeans established different institutions in different colonies depending on the mortality rate they faced. Wherever the risk of death was high and it was very costly to settle in large numbers, the Europeans established extractive institutions, i.e. institutions that did not guarantee property rights. However, they established good institutions anywhere the epidemiological 
environment favored permanent settlement. In another article, the same authors (Acemoglu et al., 2002) complete the picture by adding the density of native population and the abundance of natural resources. These factors determined whether the territory could be exploited for large rent extraction. In this case, the Europeans preferred to set up institutions that did not guarantee property rights.

Rodrik et al. (2004) jointly considered geography, trade and institutions as main determinants of economic growth. They instrument institutions using Acemoglu et al.'s approach and trade through the variables proposed by Frankel and Romer (1999). In their words, "these two instruments, having passed what might be called the American Economic Review (AER)-test, are our best hope at the moment of unraveling the tangle of cause and effect relationship involved". Their conclusion is that "institutions trump geography and openness".

A literature beginning with La Porta et al. (1997) emphasizes the importance of legal origins (Common Law versus Civil Law) as determinants of later economic success. Differences in legal origins translate into substantive differences in policy and economic outcomes (La Porta et al. 1997, 1998), in particular financial development and greater judicial independence (La Porta et al. 2004). These indicators are, in turn, associated with better contract enforcement and greater security of property rights. La Porta et al. (2007) summarize a decade long investigation along these lines and report the main findings: common law is associated with improved financial development, better access to finance, less government ownership and regulation which, in turn, are associated with less corruption, more well-functioning labor markets and smaller black markets. Common law countries also exhibit a more independent and less formalized judicial system which implies more secure property rights and better contract enforcement.

Glaeser et al. (2004) suggest human capital to be the core driving force of economic growth. Partly criticizing Acemoglu et al. (2001, 2002), they argue that the settlers did not only bring with them their institutions (i.e. constraints on the executive) but also factors such as human capital. The empirical evidence presented in their paper supports this claim. There is a strong correlation between economic growth and human capital (measured as years of schooling) both now and in the year 1900 and human capital also has a strong correlation with settlers' mortality. The authors suggest that a more comprehensive approach is called for. The idea that settlers did not only bring constraints on the executive power but also human capital and perhaps social norms is particularly interesting. However, Glaeser et al. (2004) have not answered the question of why mortality has such a strong correlation with measures of human capital. Furthermore, they do not explain why British colonies appear to have systematically outperformed French and Spanish ones. Nor is it sufficiently clear what the settlers brought in addition to human (and, of course, physical) capital.

This paper reconciles the insights of Glaeser et al. (2004) with those of Acemoglu et al. (2001). In the next section, I will propose a theory that brings together these different pieces of evidence under a new interpretation, which hopefully contributes to a better understanding of the colonization process and 
the ultimate causes of economic growth. I will also present empirical evidence suggesting that underlying cultural characteristics might be driving the results discussed above.

\section{The Settlement Choice}

This article builds on the following three propositions: (i) institutions, both formal and informal, explain long-run differences in cross-country economic performances; (ii) the colonial experience can be considered as a quasi natural experiment for studying the origins of political institutions; (iii) culture played an important role in co-determining colonization choice and subsequent institutional development. Previous researchers have emphasized factors such as mortality, geography and human capital that prima facie may seem unrelated to culture. I will demonstrate that these seemingly exogenous variables are, in fact, systematically related to culture through the mechanism of endogenous choice of settlement. This suggests a more comprehensive framework for the results obtained by other researchers and provides a new interpretation for other empirical regularities.

What then is culture? Bednar and Page (2006a) suggest that "Culture can be defined as individual and community level behavioral patterns that depend upon context and are often suboptimal. Cultural behavior influences the performance of institutions [...] the efficacy of markets, democracies, and law hinges upon behavior, particularly the tendency for people to cooperate with and trust one another. A theory of institutions, therefore, must come to grips with culture." According to this definition, culture does not only influence the rise and persistence of formal institutions but also affects the performance of society given any set of institutions. One aspect needs to be clarified. The word institutions is usually used to refer to formal institutions, i.e. a set of formalized rules that regulates the life of a community. It is useful to distinguish between these and informal institutions. As opposed to formal institutions, informal institutions are closely related to culture and social norms and moral principles that influence individual preferences and behavior.

The idea that culture or social norms might influence institutions and hence, economic outcomes, is not new. In particular, since Weber and his "The Protestant Ethic and the Spirit of Capitalism" (Weber, 1930), the idea that protestant culture was conducive to formal and informal institutions that are beneficial for growth has been widely discussed. Not only economists but also political scientists, sociologists and historians have presented arguments and evidence in favor of or against it. Recently, Huntington (2004) and Fogel (2000) have referred to America's exceptional puritan cultural background to explain its development and success. Some of the growth literature previously discussed explicitly recognizes the importance of culture. Hall and Jones (1999) associate good institutions with European influence, even though they do not distinguish among Europeans. The theory of legal origins distinguishes between legal systems, one relevant cultural dimension, and uses these differences to explain various economic outcomes. The theory proposed 
by Acemoglu, Johnson and Robinson (2001) can also be revisited and brought in line with the intuition that underlying cultural elements influence various institutional and economic outcomes. The apparent contradiction between the results of Acemoglu et al. and other works can be reconciled by recognizing the influence of cultural elements in both works, as suggested by the rest of this article.

Acemoglu and his coauthors attribute differences in institutional arrangements across colonies to variation in mortality rates: higher settler mortality is associated with lower institutional quality. Lacking any interest in settling down in territories with unfavorable conditions, the Europeans chose to establish institutions not leading to economic growth. However, there is another mechanism that could explain the same pattern in the data but is based on a somewhat different theory. This mechanism is best seen not as opposite to the one proposed by Acemoglu et al. but as complementary. The idea is that different settlers chose to migrate to different colonies, based on exogenous attributes of the destinations. The Europeans did not randomly end up in one colony or another; they selected their destinations beforehand. This selection process co-determined the types of settlers that ended up in various colonies and their subsequent institutional development. Thus, British settlers planning long-term non-expropriating economic policies did not end up in colonies suitable for this purpose, such as North America and Australia, by chance. Conversely, Spanish settlers looking for short-term profit based on mining and exploitation did not contest or seek out sparsely populated New England but headed for mining colonies in the Andes and plantation economies in Central America.

This idea explicitly accounts for heterogeneity across settlers or European countries. The implicit assumption behind the theory that institutions were mainly established based on settlers' survival probability is cultural or preference homogeneity. It is thus assumed that Europeans were similar in terms of preferences, ideology and national-social values. It also assumed that different countries employed similar colonial policies, implicitly assuming that only the exogenous attributes of the colonies were different and that these differences were allocated in a lottery-like process. Rather than being homogeneous, Europeans varied significantly in terms of culture and national policies. Englishmen were not only endowed with a different set of values as compared to Spanish or French colonists, England also employed different colonial policies than the continental powers. It is important to notice that this theory does not claim that settlers were homogenous within a country or that each European nation followed only one colonial policy. Some British settlers moved to the Caribbean Island and created plantations similar to those run by their Spanish counterparts. French colonists moved to Canada and built a prosperous community before becoming part of the British Commonwealth. The idea is that certain groups were more prominent in certain European nations rather than others (or maybe more politically important) and that these differences had important impacts on European colonization ventures as described above.

This theory about the origins of colonial institutions reconciles the intuition of Glaeser et al. (2004) that settlers brought with them more than formal institutions (hence, the relation between human capital and settlers' mortality as described in their article) with the empirical regularities discovered by Acemoglu et al. 
(2001, 2002). The negative relation between mortality and growth is confirmed in this paper; however, I also find that, rather than being a completely exogenous instrument, mortality is a function of colonial origin. Similarly, human capital is confirmed to be a source of growth, but once more, I found that human capital itself is determined by colonial origin. The idea is not to replace exogenous factors or human capital with colonial origin, rather the data points to a process of co-determination. These findings point to the need for expanding the theory of colonial institutions and growth to encompass colonial origins. Before making a careful description of these empirical patterns, I will turn to a theoretical discussion.

\subsection{The Origins of Colonial Institutions}

It is possible to identify at least three mechanisms explaining the origins of colonial institutions. A first simple possibility is that the Europeans adopted the "native" institutional framework, usually extractive institutions; they became the new masters. It could be argued, though, that native populations responded to the same incentives as described above regarding survival probability or population density: the natives created "bad" institutions in territories with high mortality or where remarkable rents could be extracted. This would explain why regions like Peru or Mexico effectively had extractive institutions before the arrival of the Europeans. However, this fails to explain the situation in North America. Why did native Americans living in territories with abundant land, scarce labor and low mortality not establish the same "property rights institutions" that the Europeans were going to set up? The reason is straightforward. First, advanced property rights institutions had not yet been developed by the native cultures, including the most advanced of these nations such as Inca, Maya and Iroquois. Second, the colonizers (per definition) took political power and determined their preferred institutions. This raises the question: if sizable differences existed between Europeans and natives in terms of institutional development, is it possible that smaller, but still important, dissimilarities existed among Europeans?

The second mechanism is outlined by Acemoglu et al. (2001) who indeed attribute the origins of colonial institutions to European settlers. Under favorable conditions, they established "good" institutions. However, when permanent settlement was costly, more extractive institutions were preferred. As previously argued, my empirical findings suggest that this theory - while capturing important aspects of history - should be complemented with a selection model of settlers. Settlers were rather heterogeneous in their individual and social characteristic and chose different territories to migrate to. The same heterogeneity led to different colonial policies. The theory of Acemoglu et al. (2001) with mortality and other exogenous variables as the main determinants of colonial institutions is arguably the most widely accepted for explaining colonial institutions (Rodrik et al. 2004). It should be emphasized that the theory proposed in this article and the empirical findings do not invalidate this mechanism. Rather they supplement it by extending the process one step backward; even when controling for colonial institutions mortality remains a significant albeit weaker factor. 
The third mechanism is what I refer to as the settler self-selection process. People with different personal values and norms gravitated toward different overseas territories. Individuals held different views about the extent of government intervention, the importance of religion, the emphasis on individual-responsibility and different work ethics, for example. As an historical example, consider the differences in values between puritan small farmers in New England and Spanish landlords on the Pampas. The institutions in the colonies then mirrored the values and views of the initial immigrants, i.e. the norm-setting settlers (Huntington, 2004). The Europeans conquered "virgin" territories and imposed their norms and rules on local populations. Thus, they wrote their own Rousseauian contract (Rousseau, 1762), making each colonial enterprise unique.

Exogenous, geographical characteristics, such as mortality or population density, influence institutions by selecting the type of settler most likely to colonize a given region. Settlers' mortality and population density or urbanization should correlate with different types of settlers. Moreover, if settlers' types are correlated with national or religious identity, mortality will influence the likelihood of being colonized by a certain European country (religious type). The next few sections of this article will suggest this to indeed be the case.

Colonial institutions were also influenced by the home country. The home country could influence overseas institutions by regulating the flow of migrants, thereby influencing the type and the number of settlers migrating, or through laws and regulations. Many factors obviously influenced colonial policies, for example national culture and national institutions, e.g. how powerful the king was, political equilibria and the structure of the economy, e.g. the importance of the mercantile class. These factors influenced the choices of the European countries in terms of which territories to colonize. They also influenced the colonial policies adopted toward overseas provinces. A clear example is given by the liberal emigration and land grants policies adopted by England versus the relatively more restrictive policy adopted by Spain.

Engerman and Sokoloff (2000) describe Spanish colonization as follows. "Spanish authorities adopted the approach of distributing enormous grants of land, often including claims to a stream of income from the native labor residing in the vicinity, and of mineral resources among a privileged few". Spanish colonization policy was centralized and encouraged Spanish colonists to go wherever there were large rents to be extracted. They continue: "Spain focused its attention on [...] colonies such as Mexico and Peru, whose factor endowments were characterized by rich mineral resources and by substantial numbers of natives surviving contact with Europeans colonizers"; Spain applied "restrictive immigration policies [...] to her colonies". It seems that Spanish colonists and government chose the overseas territories that were most profitable for establishing extractive institutions. Engerman and Sokoloff continue: "the contrast between the United States and Canada, with their practices of offering small units of land for disposal and maintaining open immigration, and the rest of the Americas, where land and labor policies led to large landholdings and great inequality, seems to extend across a wide spectrum of institutions and other government interventions".

Similarly, Veliz (1994) analyzes the differences between Latin America and British America at length. He 
explains the differences between the northern and the southern parts of America using the profound cultural differences between Spain and England. Such deep differences between the two super-powers of the sixteenth and seventeenth centuries, in the author's words, are summarized by their two great cultural achievements, the Industrial Revolution and the Counter-Reformation. While England promoted and embraced a change that was bound to have an overwhelming impact on Europe and the rest of the world, Spain's greatest achievement was a movement toward the restoration of the old order. The British brought to America a stubborn ability to thrive on diversity and change that was entirely consistent with their entrepreneurial and mercantilist culture. The Iberians, in contrast, brought a cultural tradition shaped like a vast baroque dome, a monument to their successful attempt at arresting the changes that threatened their imperial moment.

To emphasize the importance of the origins of colonists, consider that much of the southern part of Latin America resembles United States and southern Canada in terms of abundance of land and climate. Similarly, there are few intrinsic differences between northern Mexico and the south-western parts of the United States. Despite this, the institutions are clearly very different in these examples. It would appear that deeper causes, such as colonial policies or settler type, must be taken into account to explain the institutional divergence between North and South America. The restrictive immigration policies embraced by the Spanish crown constitute an example of limits imposed on the type of Spanish settler that was willing to immigrate to the New World in order to create new wealth through work and entrepreneurship. The Spanish crown simultaneously encouraged emigrants who planned to exploit local resources and populations. Similar policies and emigration patterns applied to Africa and Asia.

It is a cliché but nevertheless true and informative that long-term productive settlers, such as the Puritans, were far more common in England than in contemporary Spain, France or Portugal.

\subsection{Mortality, Culture and Institutions}

The theory described above ties together pieces of evidence from different sources. Variation in mortality levels seems to be systematically related to differences in economic outcomes. Other evidence links variations in institutional quality and economic outcomes to human capital (Glaeser et al. 2004). In addition, there is a well established literature on the importance of culture and social norms (Guiso et al., 2003). Even though these concepts are hard to capture and measure in a stringent way, norms and values are important economic variables (Guiso et al., 2007). In addition to direct influence on economic behavior, it seems plausible that cultural variables play a part in both institutions and the accumulation of human capital.

The theory proposed in this article is thus that exogenous variables such as mortality determined the type of settlers drawn to various territories. The settler type, in turn, influenced institutions and the accumulation of human capital. Economic outcome was a function of formal institutions (determined by settler type and exogenous characteristics), informal institutions such as culture and norms (determined by 
settler type) and human capital accumulation (once more influenced by settler type). This theory reconciles two strands of the previous literature while doing a better job at explaining the data. While previous literature presented extensive evidence regarding the relationship among culture, institutions, human capital and economic outcomes, there is little or no evidence of the relation between mortality, other geographical characteristics and cultural types. I will first focus on this last piece of empirical regularity and then discuss the relationship between culture and institutions. Colonialism is an almost ideal quasi-experiment for studying the impact of culture on institutions and economic outcomes. The next section will show that the anecdotal observation that the more successful colonies are also those with an British colonial background, is supported by a more sophisticated data analysis. Institutions, especially informal institutions, the nonwritten rules of behavior and social norms, are embedded in individual preference functions (Becker and Murphy, 2000). These can change over time, under the pressure of technological change or broader social forces, but are taken as given by individuals in the short and medium term, often for their entire life. As in Acemoglu et al. (2001), institutions are persistent over time and institutions established in colonial periods survived until modern times, with minor changes. The reason for this persistence is clear: formal and informal institutions are part of the cultural heritage of a group; they reflect deeper beliefs about the existence of the community. Institutions are transmitted from generation to generation as part of the shared views of society; they help define the identity of individuals and improve the workings of a society, decreasing the information and transaction costs.

This article investigates how the probability of colonization of a country with certain geographical conditions is influenced by the cultural characteristics of settlers. While it is hard to measure culture or social norms today, it is yet harder to find suitable proxies going back to colonial times. Ideally, we would like to observe individual characteristics of colonists, measures of their social values, their individual norms and perhaps also their political ideology. No such detailed data are available for that period. Instead, I will rely on nationality and religion as imperfect measurements of settler type (Weber 1930, Huntington 2004). Religious and civil norms are, per definition, strongly ingrained in a person's mind and influence private and public actions. Moreover, they are stable over time and only change gradually. I will also use other variables proposed by La Porta and his coauthors, namely the type of legal system existing in the colonies. While the literature on legal origins is focused on evaluating the independent contribution of the legal system to economic development, here they will be used as proxies of culture. Ideally, we would like to have measures of human capital which would allow us to evaluate whether settlers with different human capital chose to go to different colonies. Glaeser et al. (2004) provide some measures for human capital whose usefulness will be discussed later.

There are advantages and disadvantages in using national or religious proxies for culture. The main disadvantage is that, to some degree, the cultural aspects that are conducive to good institutions and economic growth remain hidden. If we could observe individual characteristics, we could discriminate among 
settlers with views favoring property rights and contracts enforcement and settlers with other fundamental beliefs. National culture heritage will instead only be suggestive of a certain type of settler and culture (Weber, 1930; Huntington, 2004). The national identity dummies will, in fact, represent the fact that some countries were more likely to send a certain type of settlers rather than sending them with probability one. Clearly, not all Protestant settlers fit the ideal description given by Weber in terms of social norms and work ethics. However, it is reasonable to assume that they fit this description better than non-Protestants.

The main advantage of using national dummies for culture is that they are likely to capture both individual and political differences in colonial type as previously described. It should be kept in mind that national types will not allow us to separate the impact of state policies and the differences in the immigrants' culture. An historical example would be how a colony settled by protestant French Huguenots in a geographically fertile and low mortality region would have compared to Haiti or a French African colony. No such historical experiment exists.

\section{Data and Specifications}

We can represent the settlers' (or countries') choice following the standard theory of discrete regression models (Maddala, 1983). Let us consider an underlying response variable, $y_{i}^{*}$, defined by the regression relationship:

$$
y_{i}^{*}=\beta^{\prime} x_{i}+u_{i}
$$

The variable $y_{i}^{*}$ measures the net utility of colonizing a territory, vector $x_{i}$ contains the exogenous characteristics that explain the colonization choice (mortality, latitude, average temperature, population density etc) and $u_{i}$ is an error term. In practice, the variable $y_{i}^{*}$ is unobservable. Instead, we observe a dummy variable, $y_{i}$, defined by

$$
\begin{aligned}
& y_{i}=1 \quad \text { if } \quad y_{i}^{*} \geq 0 \\
& y_{i}=0 \quad \text { if } \quad y_{i}^{*}<0 .
\end{aligned}
$$

The probability of the dummy variable being equal to one, i.e. of a given territory being colonized by a certain type of settler, is given by:

$$
\operatorname{Pr}\left(y_{i}=1 \mid x_{i}\right)=\operatorname{Pr}\left(u_{i}>-\beta^{\prime} x_{i}\right)=1-F\left(-\beta^{\prime} x_{i}\right)
$$

where $F$ is the cumulative distribution function for $u$. I estimate this probability using probit and logit models, the only difference being the assumed density function for the errors. Since the results are qualitatively the same, I will only report the results from the probit analysis. ${ }^{1}$

\footnotetext{
${ }^{1}$ The results are obtained by a probit model. The logit specification is not reported because it delivers the same results, but it is available on request. Amemiya (1981) suggests that multiplying the logit estimates by $1 / 16=0.625$ produces a close approximation between the two models and makes the coefficients comparable.
} 
The dependent variables are dummy variables classifying the European States into Protestant versus Catholic, or Common Law versus Civil Law. Moreover, there are dummies representing the nationality of each colony's home country. Only England, Spain and France had enough colonies to be analyzed separately, and Spain barely so. I run a separate probit regression for each of them. The independent variables are mortality, urbanization, population density, latitude and natural resources. Due to lack of data, a complete probit analysis of choices using human capital as the independent variable could not be performed. However there is some evidence that there might be a similar ongoing process.

The data are the same as those used in previous works. The mortality data, national and religious dummies and various other control variables, such as latitude, urbanization, populations density and natural resources, are taken from Acemoglu et al. (2001). The human capital measures and different institutional proxies are taken from Glaeser et al. (2004). The dummies for legal systems are constructed following La Porta et al. (2007). A description of the variables used is given in the Appendix.

\subsection{Other Specifications}

Running a probit regression separately for England, Spain and France is based on the assumption that the policies of these three countries are independent of each other in terms of colonization outcomes. To some extent, this is a reasonable assumption since there are only three major countries that have successfully carried out colonial expansions. ${ }^{2}$ Robustness checks are performed on the assumption of independence. It is possible that the policy of each country had some influence on the choices of the others. For example, once one territory was colonized by one country, the other European kingdoms had no access to that land unless they started a war against the initial colonizers. The choices depended on other factors, such as relative military strength and maritime resources. One way of taking this interdependence into account is to run a multinomial logit regression. The multinomial model treats the choices of the three countries as interdependent. Instead of having three separate regression for the three countries, I only perform one regression whose dependent variable is not a dummy variable, but a variable that takes on three values $(0,1$ and 2), one for each country. The multinomial logit jointly calculates the probability of each realization.

A second way of controling for possible interdependence is the division of the original sample into subsamples based on the colonization period. For each territory, the colonization date can be found in historical records. I used the on-line version of Encyclopaedia Britannica and consider the date in which any European country established a permanent outpost in the relevant area as the colonization date. I constructed three

\footnotetext{
${ }^{2}$ Netherlands and Portugal are the two main other colonial nations in the period discussed. Russia was in some sense so successful that the colonial episode is indistinguishable from a simple expansion of national boundaries. Smaller European nations such as Sweden and Denmark failed to establish any major colonies. Germany, Italy and Belgium did establish colonies, but much later than what is commonly assumed. This colonial period only lasted a little more than half a century. All these countries are included in the sample.
} 
subsamples. The first subsample contains all territories that were colonized before or in 1896 . The 1896 date represents the $85 \%$ percentile of the colonizations dates. The second subsample contains the territories colonized between 1530 (the 10th percentile) and 1898 (the 90th percentile). The third subsample contains all territories colonized after 1533 (15th percentile). I then run the probit and logit models described above on the three subsamples. This division into smaller periods of time is meant to capture that at any given point in time, not all possible countries were available for colonization either because some of them still remained to be discovered or because somebody already occupied them.

The results may, in principle, be sensible to the choices of dates but, in practice, this does not seem to be the case. The main problem is clearly the small size of the sample. This imposes some limitations on this type of exercise, such as the number of subsamples that can be considered.

\section{Mortality, Culture and Institutions}

\subsection{Mortality and Culture}

Tables 1 and 2 report the coefficient and the marginal effects estimated for Protestants. Note that since Catholic colonies are those that are not Protestant, the results (not reported) are the same but with the reverse sign. Tables 3 and 4 report the same for Common Law colonies while the same applies for Civil Law colonies as for Catholic colonies. Tables 5 to 10 concern England, France and Spain. The first specification only considers mortality as an exogenous factor that explains the colonization choice. From the second specification I add various controls, such as demographic and geographical variables. Usually, they do not have any impact on the significance of the coefficient of mortality except in the case of Spain. These results can be explained by the smaller number of Spanish colonies and their geographical concentration in territories with homogeneous mortality levels.

Mortality explains the choice of Europeans countries overseas. British/Protestant/Common Law colonies generally became established in territories with low mortality. This suggests that British/Protestant settlers were likely to colonize places with favorable conditions for long-term settlements. French/Catholics settlers do exactly the opposite, pursuing a colonization policy that seems purely extractive. The coefficient on mortality is not always significant for Spain. When significant, it indicates that Spain or Spanish settlers were more likely to behave as their French Catholic counterparts. Controling for population density and rate of urbanization, the coefficient on mortality for Spain becomes significant and positive which suggests that given the level of native population, which represents an exploitable rent, the Spanish Crown was more likely to go to places with higher mortality.

Figures 1-7 show the probabilities, according to the different specifications, of being colonized by Protestants/Catholics or Common Law/Civil Law countries, respectively, and England, France and Spain as a function of settlers' mortality. The graphs evidentiate different colonization patterns for different religious, 
national or legal types. The evidence is in favor of a selection theory of colonization. Different countries and different settlers colonized different territories. Their differences are probably reflected in the institutions they established across their colonies. Let us look at the stark differences between England and France. We might consider the two opposite colonization patterns as an accident of history but it is more reasonable to think that values, social norms, culture and specific policies have led the two European countries to differ so sharply in their colonization preferences.

\subsection{Robustness Checks}

\subsubsection{Time Subsamples}

The division of the four centuries of colonization into smaller time periods allows us to account for the interdependence of colonization choices. As time passed, new territories became available for colonization, more lands were discovered and some were already occupied by someone else raising the cost of colonization. Given the small size of the subsamples, I ignored the difference between England, France and Spain and focused on the dichotomies Protestant versus Catholic and Common Law versus Civil Law. The estimated coefficients, marginal effects and probabilities in all subsamples support the results of the previous section. Tables 11-22 are for Protestant and Common Law countries, coefficients and marginal effects; Catholic and Civil Law colonies are non-Protestant and non-Common Law colonies, respectively, so the results are the same but with the reverse sign. The previous result, i.e. Protestant/Common Law States colonize territories with lower mortality and Catholic/Civil Law countries do the opposite, also holds in the subsamples.

\subsubsection{Multinomial Logit}

The multinomial logit model takes into account the interdependence of the colonization choices. Rather than assuming the colonization choices of the different European countries to have been made independently, as is implicitly assumed by running separate regressions for each country, the multinomial model treats British, French and Spanish choices as influencing each another. The results presented in Tables 23 and 24 generally confirm the findings from the probit analysis: England tends to colonize low mortality countries, while France and Spain prefer territories with higher mortality.

\subsection{Culture and Institutions}

Tables 25-32 show the systematic relationship between "good" indicators and British/Protestant background. Besides a higher income per capita, former British colonies have higher levels of human capital and better institutions. There are two qualifications that the reader should bear in mind. First, the evidence reported does not prove causation, it merely hints at certain underlying patterns that may be of importance. Irre-

\footnotetext{
${ }^{3}$ I only present the results obtained using England as the omitted value. The results are similar when we consider Spain or France as the omitted value.
} 
spective of whether one accepts that institutions or human capital are the ultimate causes of growth, the question of why British and Protestant background was so strongly associated with good institutions, rapid economic growth and human capital accumulation must be answered. Here, I stress the lack of good cultural measures, especially for the colonial period, as possible explanations for the difficulty in getting a definitive answer to this question. Unfortunately, due to their binomial nature, dummy variables are not very helpful when it comes to explaining variation in institutions or economic performance. Naturally, other approaches are possible but should encompass the exceptionalism of the British colonial experience.

A second qualification is already stressed by Glaeser et al. (2004). They convincingly argue that certain measures of institutions used in the literature are not proper measures of institutions, but rather indicators of the quality of policies. An example they discuss is that of a dictator that chooses to respect property rights rather than being bound to them by a Constitution (Singapore or USSR). This might suggest endogeneity arising from measurement issues. This is, however, less of a problem in the context of this article; our core propositions are not only that good norms are more likely to produce better Constitutions, but also that good norms will deliver better policies, given any Constitution. This is something peculiar as concerns norms. In particular, British/Protestants countries would tend to have better informal institutions, higher human capital and better policies, given their formal institutions. If so, even a dictator living in a society with such norms would be more likely to be a "good dictator" than a "bad dictator". British/Protestant norms have an effect both on the "extensive margin", the quality of the formal institutions and, on the "intensive margin", the quality of the policies produced by any given set of formal institutions. In a nutshell, for the purposes of this article, it is less relevant whether the variables measuring "institutions" actually measure formal institutions or the combination of formal and informal institutions. The theory of this article is that better norms deliver better Constitutions and better policies, given the Constitution. Lacking better measures of informal institutions, this is as far as we can get.

One of the likely sources of endogeneity is the possibility of economic growth inducing better institutions or that richer economies have better education systems and hence, higher levels of human capital. If the British/Protestant colonies had become richer for any other reason than their institutions or human capital, we would be drawing the wrong conclusion from Tables 25-32. Optimally, we would like to observe institutions and human capital closer to the colonization period, possibly at the establishment of the colony. We would like to study the early settlers. This does not only allow us to avoid the reverse causality problem discussed above but also to test, on another dimension, whether the theory presented in this article is reasonable. In fact, it is possible that individuals with different human capital decided to move to different colonies. Unfortunately, we do not have enough data on settlers' human capital, so we cannot look for systematic evidence like that presented above. Some data are provided by Glaeser et al. (2004). From these observations, an interesting pattern emerges in line with what has been suggested in this article about primary school enrollment and institutions in some early colonies at the end of the nineteenth century. Enrollment in primary school seems 
to be strongly related to an British/Protestant background. Primary school enrollment in British/Protestant countries on average seems higher than in the rest of the colonies across all our measures of enrollment. Of the five former colonies for which primary school enrollment in 1870 is available, four are British/Protestant and all score ten times higher than the only non-English colony. Thus, the fact that for virtually all non-English colonies we do not have any data on primary school enrollment tells us something about the level of human capital in those countries. The lack of data is, in fact, due to the lack of a widespread educational system rather than simple lack of collected data. Of the nine observations we have for primary school enrollment in 1900, four are British and five Spanish. The British colonies all score above 0.872, i.e. more than $87 \%$ of all children aged between 5 and 14 were enrolled in school, while the Spanish colonies all score below 0.324. If we look at constraints on the executive, a measure of the quality of institutions, in 1870 , of the nine observations available, the three Protestant colonies all score a seven, the highest grade indicating a greater extent of institutionalized constraints on the power of chief executives, while the remaining Catholic ones score one three and five ones; one being the lowest grade indicating unlimited executive authority. Repeating the same exercise for the year 1900, we see that the four Protestant colonies all score a seven while the remaining Catholic ones have an average of 4.84 .

This evidence suggests that the British/Protestant former colonies do not only have a higher level of human capital/better institutions today, but seem to outperform other colonies in this respect also in colonial times. It seems that the same cultural features that made early British/Protestant colonies successful in educating their population and creating better institutions in the eighteenth and nineteenth centuries still have a positive influence on them. As said before, institutions, particularly informal ones, are part of the cultural heritage of a people and tend to be transmitted from one generation to the next, especially when successful (Hayek, 1991).

Once more, these are not definitive answers but instead results that point at systematic relationships between institutions and human capital and cultural background.

\section{Conclusions}

Economic growth and institutions have been intensely studied in the last ten to fifteen years (see Asoni, 2008 for a survey). Variables that have previously been associated with good institutions or good economic outcomes seem to be systematically related to certain cultural traits. The measures of these cultural traits are not perfect and their discrete and binomial nature limits their econometric importance vis-a-vis other richer variables. This is a source of noise that gives raise to possible misinterpretations of the data. The evidence proposed above suggests that the British/Protestant culture is strongly associated with low settlers' mortality, high human capital and distance from the equator, even though this last association is statistically insignificant when controling for settlers' mortality. Each of the three variables above has been proposed as a source of economic growth, or as an instrument, in previous research. The Protestant/British background 
is also positively associated with different measures of good institutions, both today and one hundred years ago. The variables that have been found to have a profound impact on institutions and economic growth seem to be associated with each other through some deeper cultural link. This raises the question of whether all the different variables proposed are just imperfect proxies for factors that we are not yet able to measure adequately. Probably each single variable has an impact that is independent of the cultural traits it represents. This should not be allowed to conceal the more comprehensive picture, however.

The above findings are in line with the idea that institutions, especially informal institutions, are deeply embedded in people's minds. Institutions are not the result an abstract engineering process taking place when the colony is established; rather they are the expression of what people think about society and how it should be organized. Once this idea has been taken into account, it is easily understood why institutions persist over time and why similar formal institutions may perform so dissimilarly across cultural environments. This path has been little investigated so far. The evidence presented in this article, reaffirming the results from the previous literature, suggests that the quest for the causes of economic growth consists of at least three separate questions. The first regards the mechanism of economic growth, i.e. the study of those activities that create economic growth, such as accumulation of physical and human capital, trade and technological development and good institutions such as property rights and independent legal systems. A great deal of time and intellectual effort has already been spent on this question. The second question is why anecdotal and systematic evidence seems to relate most of the factors that spur economic growth to Protestantism or an British cultural background. What are the norms, the individual and collective values characterizing the intellectual and social environment that systematically stimulate behaviors and institutions conducive to economic success? Are they unique to Protestantism? How easily can they be adopted by other cultures? Culture is defined as a bundle of values and norms, so it is not clear whether different values can successfully spread across cultures. The third question is whether Protestant culture and economic growth can be separated. The evidence seems to suggest that they can indeed be separated, at least to some extent: economic growth is now more than ever a global phenomenon not restricted to former British colonies. There is undoubtedly much more to economic growth than Protestant culture. However, there are two types of economic growth: growth that comes from imitating/adopting successful models or technologies, and growth that emanates from innovation and the resulting expansion of the technological frontier. Much of world growth is arguably driven by other countries adopting originally British technology and institutions. Is this difference important in terms of analysis? Can it be related to culture or other factors? Is it just by chance that English-speaking people produced the First Industrial Revolution, the Fordist Revolution and, most recently, the ICT Revolution? Or is there something unique in the institutions created by the British? These questions naturally arise from any discussion of growth and institutions, yet remain to be answered satisfactorily. 


\section{References}

[1] Acemoglu, D. and J. Robinson.. 2000b. Why Did the West Extend the Franchise? Democracy, Inequality and Growth in Historical Perspective. Quarterly Journal of Economics 115(4): 1167-99.

[2] _ 2001. A Theory of Political Transitions. American Economic Review 91(4): 938-63.

[3] Acemoglu, D., S. Johnson, and J. Robinson. 2001. Colonial Origins of Comparative Development: an Empirical Investigation. American Economic Review 91(5): 1369-401.

[4] - 2002. Reversal of Fortune: Geography and Institutions in the Making of the Modern World Income Distribution. Quarterly Journal of Economics 117(4): 1231-94.

[5] - 2004. Institutions as the Fundamental Cause of Long-Run Growth. Prepared for the Handbook of Economic Growth edited by Aghion, P. and S. Durlauf.

[6] - 2005. The Rise of Europe: Atlantic Trade, Institutional Change and Economic Growth. American Economic Review 95(3): 546-79.

[7] 2006. Economic Origins Of Dictatorship and Democracy: Economic and Political Origins. Cambridge, UK: Cambridge University Press.

[8] Amemiya, T. 1983. Qualitative response models: A Survey. Journal of Economic Literature 19(4): 483536.

[9] Asoni, A. 2008. Protection of Property Rights and Growth as Political Equilibria. The Journal of Economic Surveys, forthcoming.

[10] Baumol, W. J. 2002. The Free-Market Innovation Machine: Analyzing the Growth Miracle of Capitalism. Princeton, USA: Princeton University Press.

[11] Becker, G. S. and K. M. Murphy. 2000. Social Economics: Market Behavior in a Social Environment. Cambridge, MA: Harvard University Press.

[12] Bednar, J. and. S. E. Page. 2006a. Can Game(s) Theory Explain Culture? The Emergence of Cultural Behavior within Multiple Games. Working Paper no 04-12-039, SFI, Santa Fe, NM.

[13] 2006b. Culture, Institutional Performance, and Path Dependence. Working Paper no WP2006-6, Institute of Governmental Studies, University of California, Berkeley, CA.

[14] De Long, J. B. and A. Shleifer. 1993. Princes and Merchants: European City Growth before the Industrial Revolution. Journal of Law \& Economics 36(2): 671-702.

[15] Dollar, D. and A. Kraay. 2004. Trade, Growth and Poverty. The Economic Journal 114(493): 22-49. 
[16] Fogel, R. W. 2000. The Fourth Great Awakenings and the Future of Egalitarianism. Chicago: University of Chicago Press.

[17] Glaeser, E. L., R. La Porta, F. Lopez-de-Silanes and A. Shleifer. 2004. Do Institutions Cause Growth?. Journal of Economic Growth 9(3): 271-303.

[18] Greif, A. 1994. Cultural Beliefs and the Organization of Society: A Historical and Theoretical Reflection on Collectivist and Individualist Societies. The Journal of Political Economy 102(5): 912-50.

[19] Guiso, L., P. Sapienza and L. Zingales. 2007. Trusting the Stock Market. Journal of Finance, forthcoming.

[20] Hall R. E and C. I. Jones. 1999. Why Do Some Countries Produce So Much More Output Per Worker Than Others? The Quarterly Journal of Economics 114(1): 83-116.

[21] Hayek, F. A. 1991. The Fatal Conceit: The Errors of Socialism. Chicago, IL: The University of Chicago Press.

[22] Huntington, S. P. 2004. Who Are We: The Challenges to America's National Identity. New York: Simon \& Schuster.

[23] La Porta, R., F. Lopez-de-Silanes and A. Shleifer. 2007. The Economic Consequences of Legal Origins. Journal of Economic Literature, forthcoming.

[24] La Porta, R., F. Lopez-De-Silanes, A. Shleifer, and R. Vishny. 1997. Legal Determinants of External Finance. Journal of Finance 52(3): 1131-50.

[25] . 1998. Law and Finance. Journal of Political Economy 106(6): 1113-55.

[26] 2002. Investor Protection and Corporate Valuation. Journal of Finance 57(3): 1147-70.

[27] Maddala, G. S. 1983. Limited-dependent and qualitative variables in econometrics. Cambridge, UK: Cambridge University Press.

[28] Mauro, P. 1995. Corruption and Growth. Quarterly Journal of Economics 110(3): 681-712.

[29] North, D. C. 1990. Institutions, institutional change and Economic Performance. Cambridge, UK: Cambridge University Press.

[30] North, D. C. and R. P. Thomas. 1973. The Rise of the Western World. Cambridge, UK: Cambridge University Press.

[31] North, D. C. and B. R., Weingast. 1989. Constitutions and Commitment: The Evolution of Institutional Governing Public Choice in Seventeenth-Century England. Journal of Economic History 49(4): 803-32. 
[32] Rodrik, D., A. Subramanian, and F. Trebbi. 2004. Institutions Rule: The Primacy of Institutions over Geography and Integration in Economic Development. Journal of Economic Growth 9(2): 131-65.

[33] Rousseau, J-J. 1762. The Social Contract. London, UK: Penguin Books.

[34] Sachs, J. 2001. Tropical Underdevelopment. Working Paper no 8119, NBER, Cambridge, Mass.

[35] Sachs, J. and A. Warner. 1995. Economic Reform and the process of Global Integration. Brookings Papers on Economic Activity 1: 1-118.

[36] Sonin, K. 2003. Why the rich may favor poor protection of property rights. Journal of Comparative Economics 31(4): 715-31.

[37] Sokoloff, K. L. and S. L. Engerman. 2000. History Lessons: Institutions, Factors Endowments and Paths of Development in the New World. Journal of Economic Perspective 14(3): 217-32.

[38] Veliz, C. 1994. The New World of the Gothic Fox: Culture and Economy in English and Spanish America. Berkeley and Los Angeles, CA: University of California Press.

[39] Weber. M. 1930. The Protestant Ethic and the Spirit of Capitalism. London, UK: Penguin Books. 


\section{Part I}

\section{Appendix}

- Average Expropriation Risk: from Glaeser et al. (2004). Risk of "outright confiscation and forced nationalization" of property. This variable ranges from zero to ten, where higher values equal a lower probability of expropriation. This variable is calculated as the average from 1982 through 1997, or for specific years as needed in the tables. Source: International Country Risk Guide at http://www.countrydata.com/datasets/.

- Colonial Dummies: Dummy indicating whether a country was a British, French, German, Spanish, Italian, Belgian, Dutch or Portuguese colony. As in Acemoglu (2001), from La Porta et al. (1999).

- Average Temperature: as in Acemoglu (2001).

- Latitude: Absolute value of latitude of the country. Measure of distance from the equator scaled to take values between 0 and 1, where 0 is the equator. As in Acemoglu (2001), from La Porta et al. (1999).

- Log European settler mortality: mortality rate of European settlers in the colony. From Acemoglu (2001).

- Years of schooling: from Glaeser et al. (2004). Years of schooling of the total population aged above 25. This variable is constructed as the average from 1960 through 2000 or, for specific years, as needed in the tables. Source: Barro, Robert J. and Jong-Wha Lee, International Data on Educational Attainment: Updates and Implications. Source: Barro and Lee (2000) Data posted on http://www.cid.harvard.edu/ciddata/ciddata.html

- Constraint on Executive: from Glaeser et al. (2004). A measure of the extent of institutionalized constraints on the decision making powers of chief executives. The variable takes seven different values: (1) Unlimited authority (there are no regular limitations on the executive's actions, as distinct from irregular limitations such as the threat or actuality of coups and assassinations); (2) Intermediate category; (3) Slight to moderate limitation on executive authority (there are some real but limited restraints on the executive); (4) Intermediate category; (5) Substantial limitations on executive authority (the executive has a more effective authority than any accountability group but is subject to substantial constraints by them); (6) Intermediate category; (7) Executive parity or subordination (accountability groups have effective authority equal to or greater than the executive in most areas of activity). This variable ranges from one to seven, where higher values equal a greater extent of institutionalized constraints on the power of chief executives. This variable is calculated as the average from 1960 through 2000, or for specific years as needed in the tables. Source: as in Jaggers and Marshall (2000).

- GDP per capita: from Glaeser et al. (2004). Gross domestic product over population. Source: Aten et al. (2002). Data available on-line at: http://pwt.econ.upenn.edu/ (this paper uses data from the 04-06-2003 version). GDP per capita for the 1870-1950 periods comes from Maddison (2003). 
- Constitutional Review: from Glaeser et al. (2004). Constitutional review is computed as the sum of two variables. The first variable measures the extent to which judges (either Supreme Court or constitutional court) have the power to review the constitutionality of laws in a given country. The variable takes three values: 2 - if there is full review of constitutionality of laws, 1 - if there is limited review of constitutionality of laws, 0 - if there is no review of constitutionality of laws. The second variable measures (on a scale from 1 to 4) how hard it is to change the constitution in a given country. One point each is given if the approval of the majority of the legislature, the chief of state and a referendum is necessary to change the constitution. An additional point is given for each of the following: if a supermajority in the legislature (more than $66 \%$ of the votes) is needed, if both houses of the legislature must approve, if the legislature must approve the amendment in two consecutive legislative terms or if the approval of a majority of state legislature is required. This variable is normalized from zero to one where higher values equal a higher degree of constitutional review by the courts. This variable is measured as of 1995. Source: La Porta et al. (2004).

- Judicial Independence: from Glaeser et al. (2004). Judicial independence is computed as the sum of three variables. The first variable measures the tenure of Supreme Court judges (highest court in any country) and takes a value of 2 - if tenure is lifelong, 1 - if tenure is more than six years but not lifelong, and 0 - if tenure is less than six years. The second measures the tenure of the highest ranked judges ruling on administrative cases and takes a value of 2 - if tenure is lifelong, 1 - if tenure is more than six years but not lifelong, 0 if tenure is less than six years. The third variable measures the existence of case law and takes a value of 1 if judicial decisions in a given country are a source of law and 0 otherwise. The variable is normalized from zero to one where higher values equal a higher degree of judicial independence. This variable is measured as of 1995. Source: La Porta et al. (2004).

- Autocracy: from Glaeser et al. (2004). This variable classifies regimes based on their degree of autocracy. Democracies are coded as 0, bureaucracies (dictatorships with a legislature) are coded as 1 and autocracies (dictatorship without a legislature) are coded as 2. Transition years are coded as the regime emerging afterwards. This variable ranges from zero to two where higher values equal a higher degree of autocracy. This variable is measured as the average from 1960 through 1990; or for specific years as needed in the tables. Source: Alvarez et al. (2000).

- Primary School Enrollment: from Glaeser et al. (2004). This variable measures primary school enrollment as a percentage of children aged 5 through 14. Measured in 1870, 1890, and 1900. Source: Lindert (2001). 
Figure 1: Predicted probability of being colonized by a protestant country for a given level of settler mortality
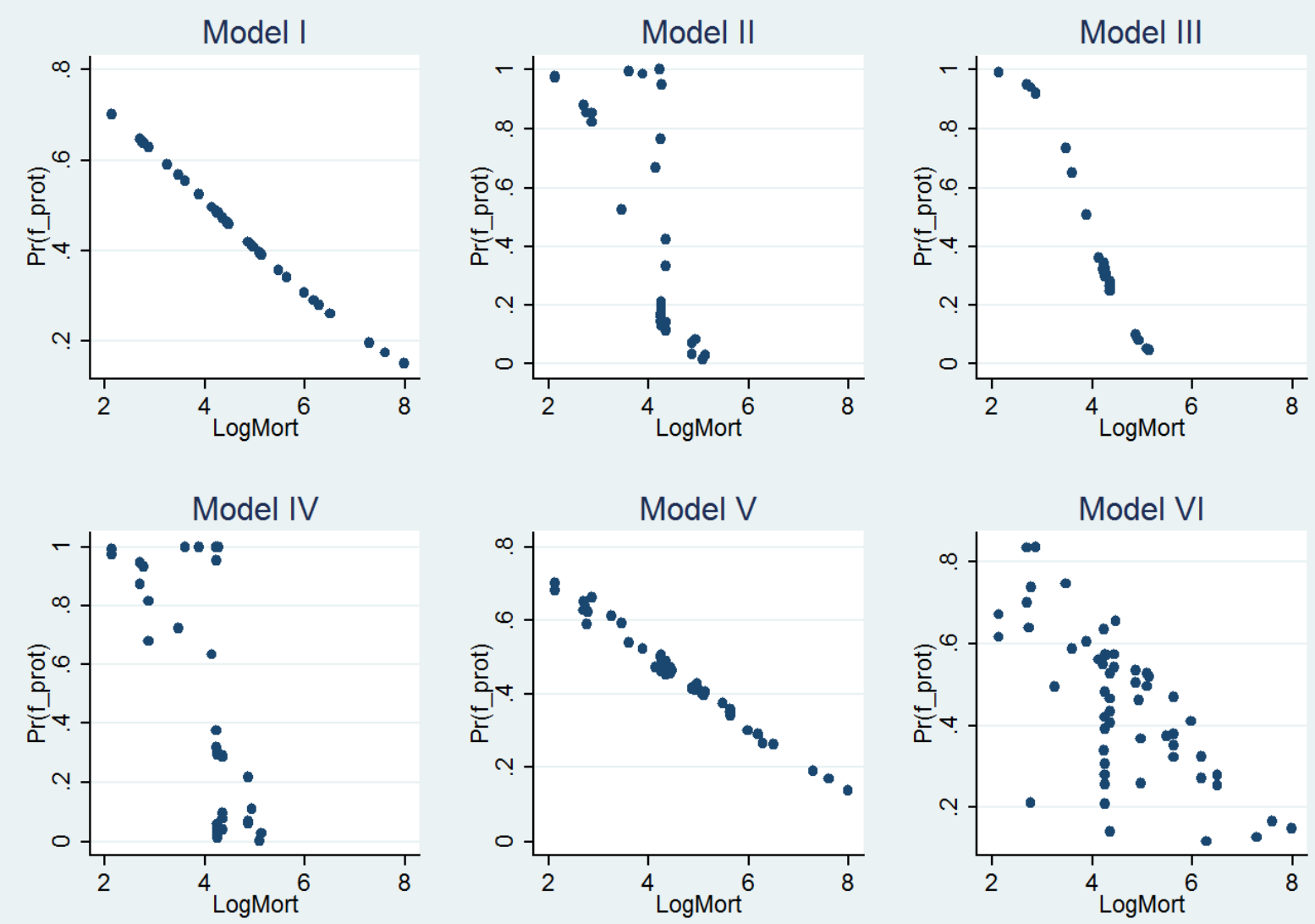
Figure 2: Predicted probability of being colonized by a catholic country for a given level of settler mortality
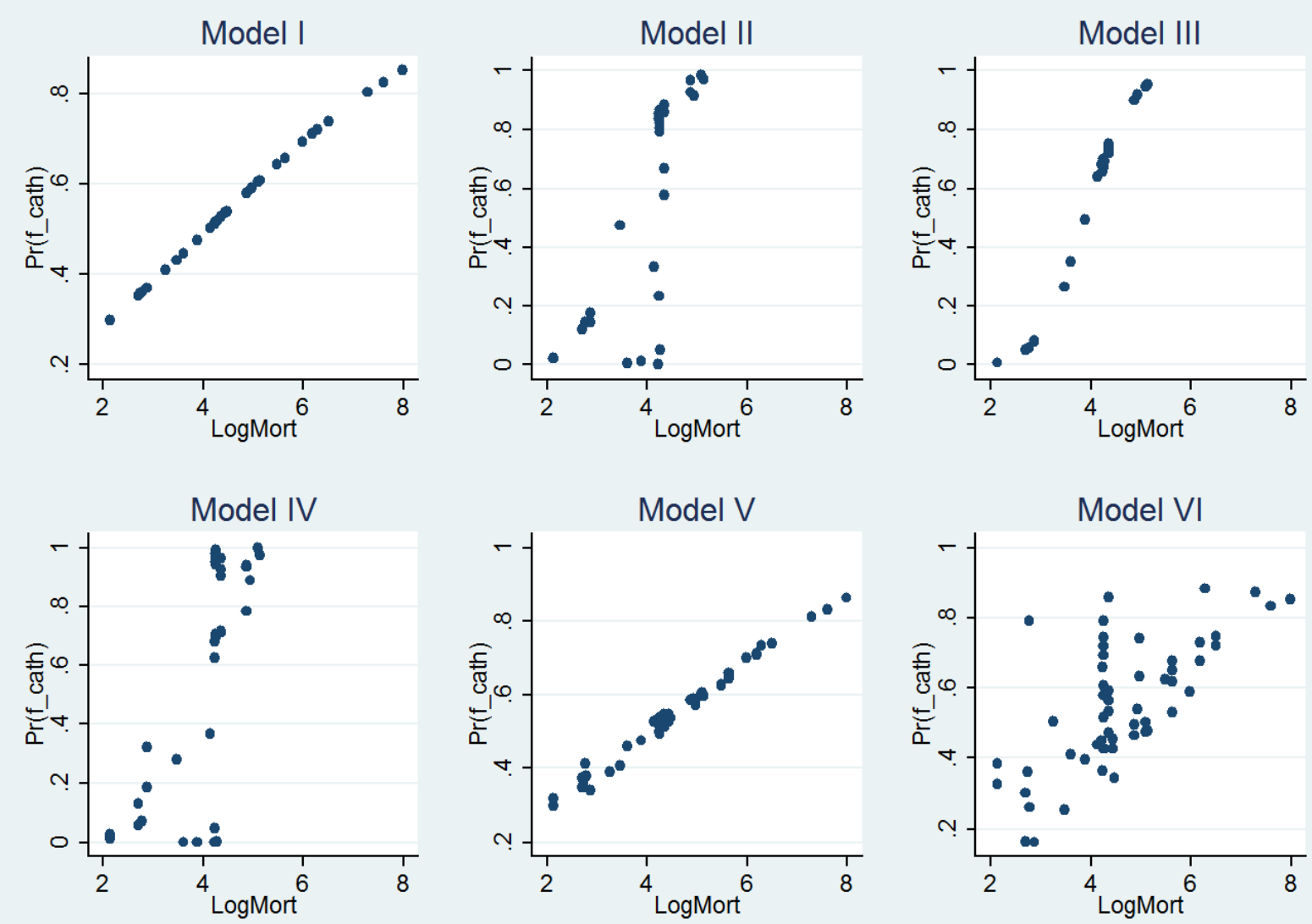
Figure 3: Predicted probability of being colonized by a common law country for a given level of settler mortality

Model I

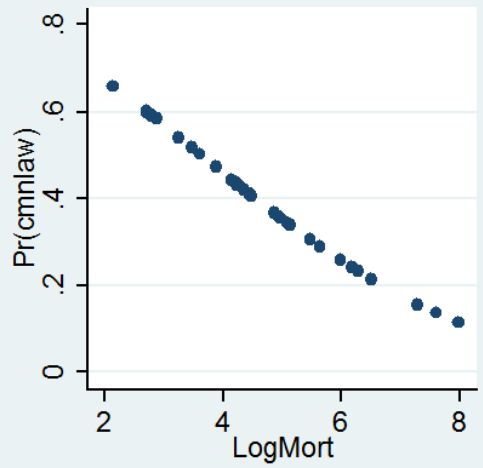

Model IV

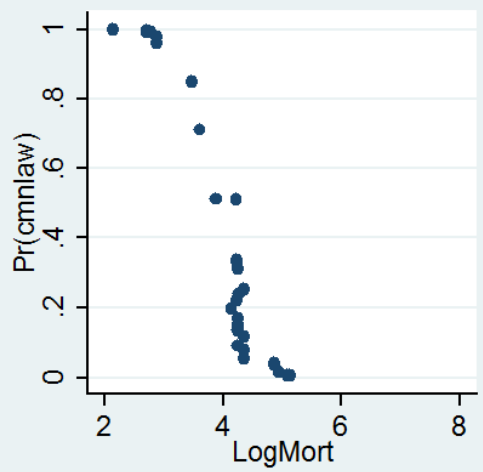

Model II

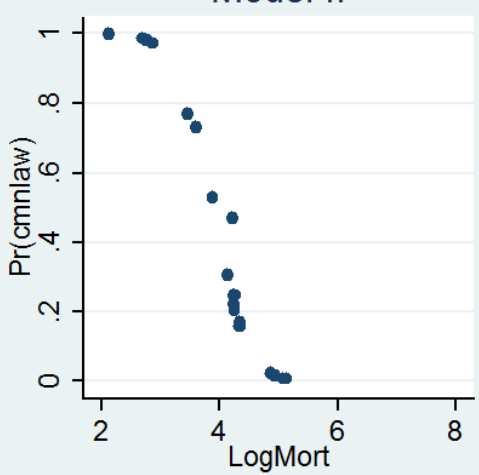

Model V

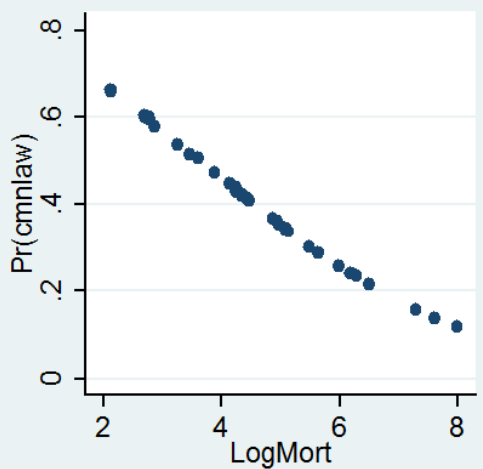

Model III

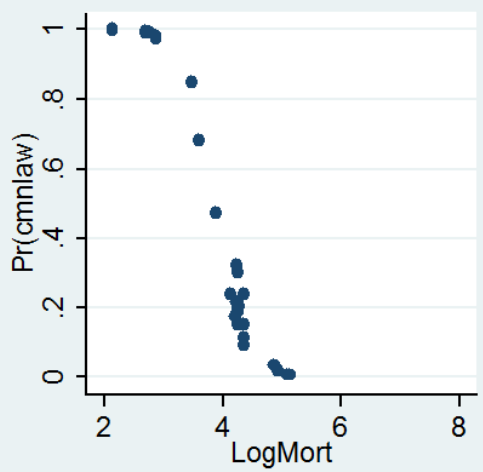

Model VI

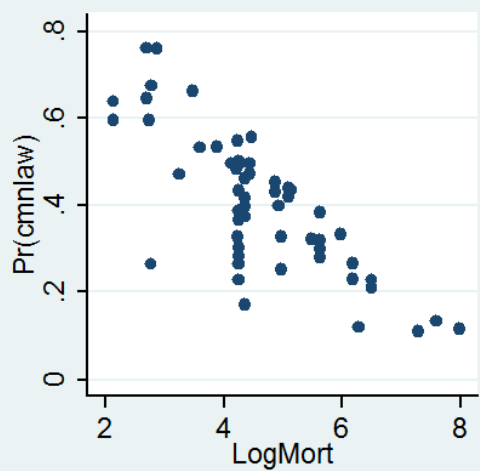


Figure 4: Predicted probability of being colonized by a Civil Law country for a given level of settler mortality
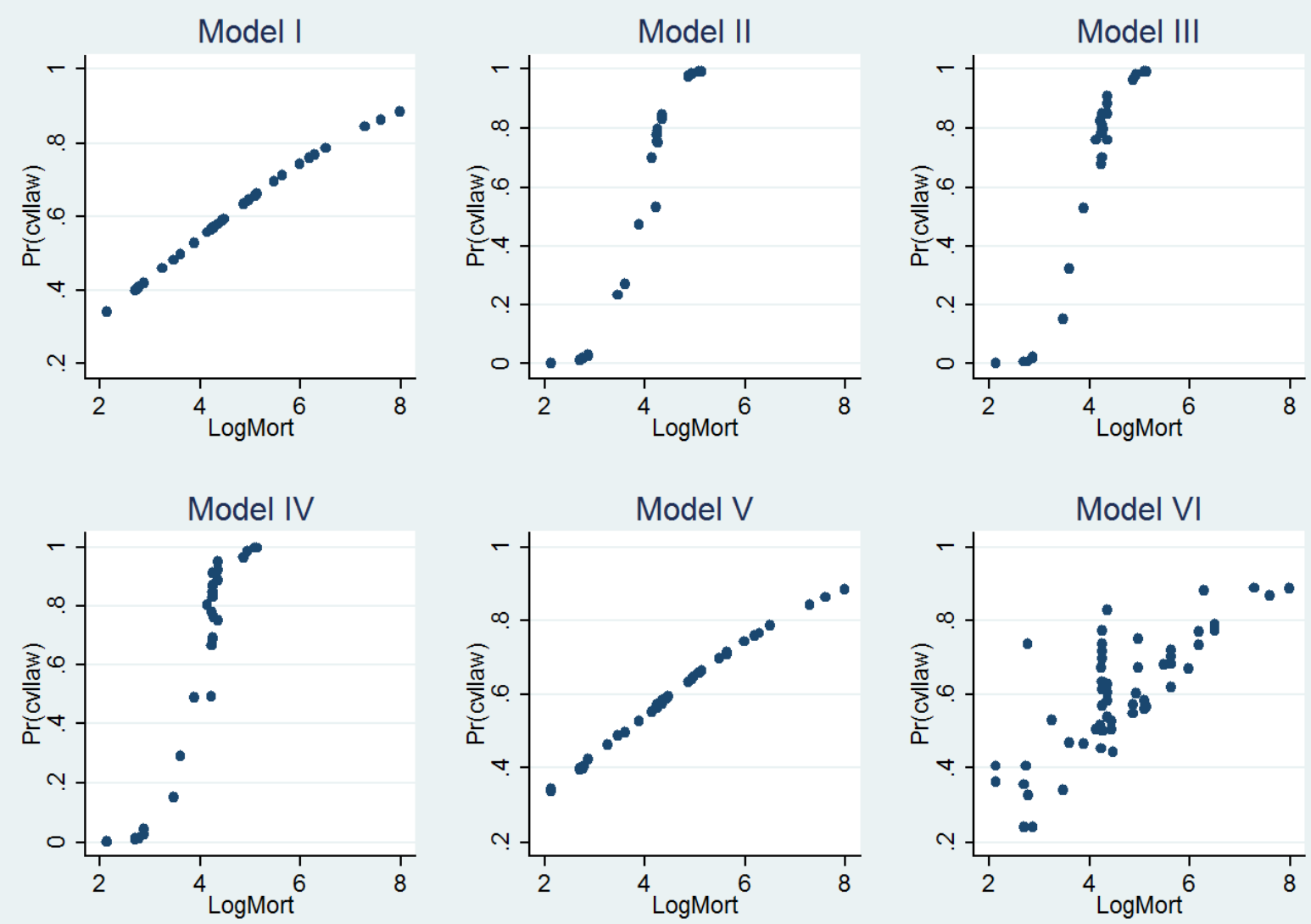
Figure 5: Predicted probability of being colonized by England for a given level of settler mortality
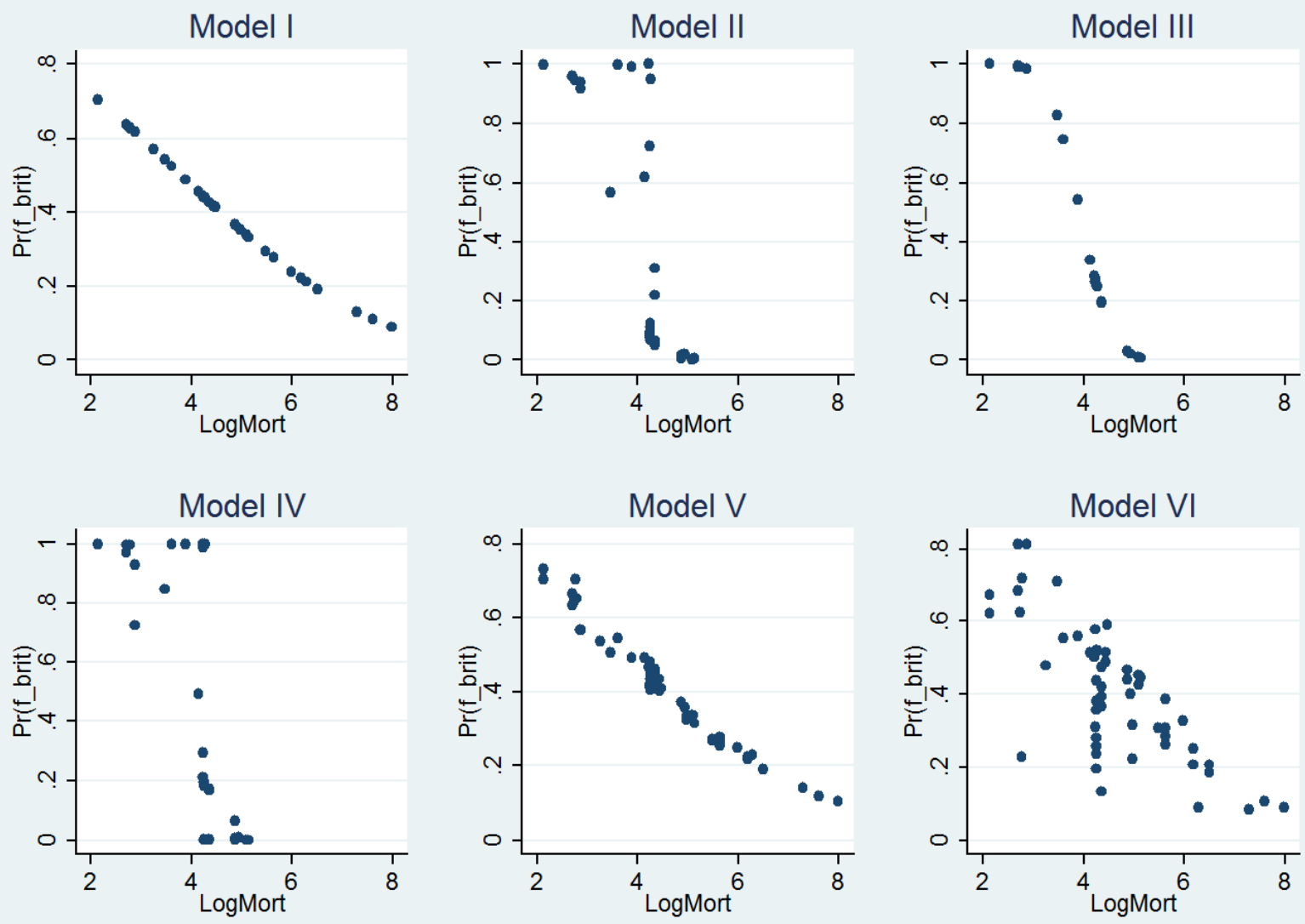
Figure 6: Predicted probability of being colonized by France for a given level of settler mortality
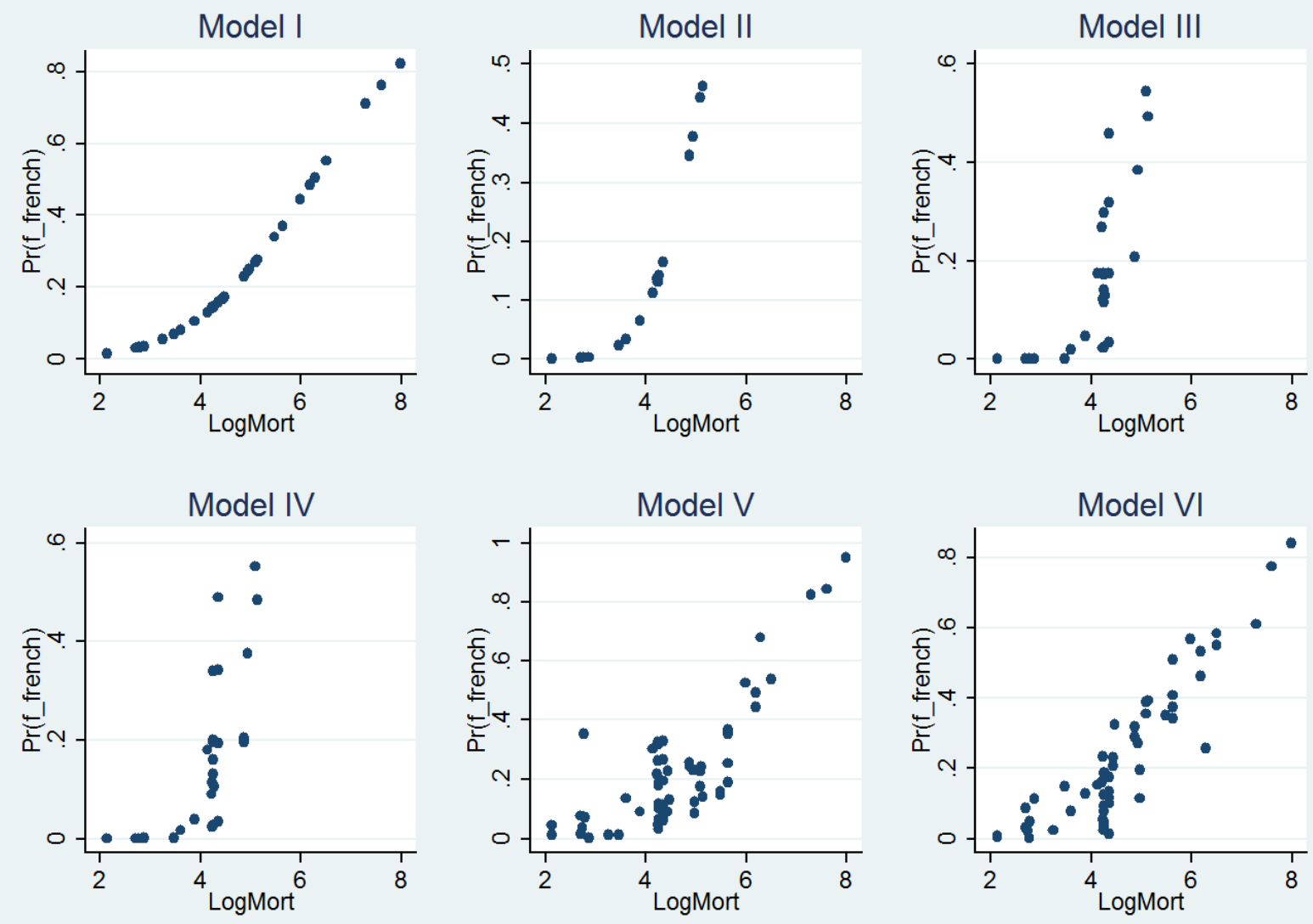
Figure 7: Predicted probability of being colonized by Spain for a given level of settler mortality
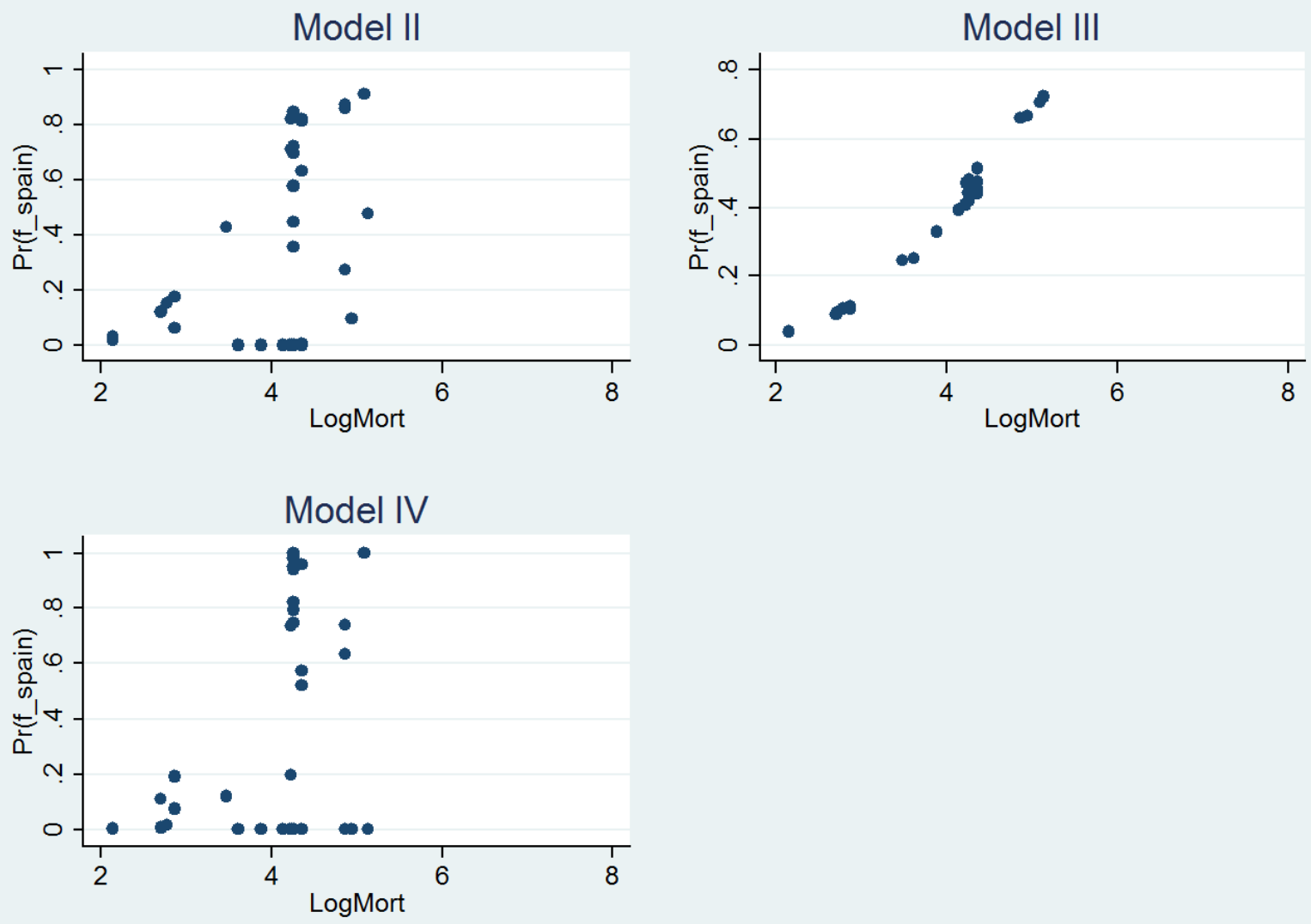
Table 1

Probit regression: the dependent variable is dummy indicating whether the colonizer was a protestant country.

\begin{tabular}{|c|c|c|c|c|c|c|c|}
\hline \multicolumn{8}{|c|}{ Protestants: Coefficients } \\
\hline & 1 & II & III & IV & V & VI & VII \\
\hline \multirow[t]{2}{*}{ Mortality } & -0.268 & -1.461 & -1.352 & -1.362 & -0.284 & -0.413 & -0.172 \\
\hline & {$[0.133]^{* *}$} & {$[0.409]^{* * *}$} & {$[0.451]^{* * *}$} & {$[0.437]^{* * *}$} & {$[0.149]^{*}$} & {$[0.155]^{* * *}$} & [0.145] \\
\hline \multirow[t]{2}{*}{ Pop. Density } & & 0.117 & & 0.229 & & & \\
\hline & & {$[0.057]^{* *}$} & & {$[0.119]^{*}$} & & & \\
\hline \multirow[t]{2}{*}{ Urbanization } & & & -0.006 & -0.159 & & & \\
\hline & & & [0.049] & {$[0.087]^{*}$} & & & \\
\hline \multirow[t]{2}{*}{ Gold } & & & & & & & 0.069 \\
\hline & & & & & & & [0.291] \\
\hline \multirow[t]{2}{*}{ Iron } & & & & & & & 0.282 \\
\hline & & & & & & & [0.427] \\
\hline \multirow[t]{2}{*}{ Silver } & & & & & & & -0.143 \\
\hline & & & & & & & [0.192] \\
\hline \multirow[t]{2}{*}{ Zinc } & & & & & & & 0.058 \\
\hline & & & & & & & [0.313] \\
\hline \multirow[t]{2}{*}{ Aver. Temp. } & & & & & & 0.076 & \\
\hline & & & & & & {$[0.037]^{* *}$} & \\
\hline \multirow[t]{2}{*}{ Latitude } & & & & & -0.337 & & \\
\hline & & & & & [1.395] & & \\
\hline \multirow[t]{2}{*}{ Constant } & 1.101 & 5.113 & 5.319 & 5.265 & 1.237 & 0.036 & 0.582 \\
\hline & {$[0.640]^{*}$} & {$[1.676]^{* * *}$} & {$[1.899]^{* * *}$} & {$[1.788]^{* * *}$} & [0.853] & [0.820] & [0.717] \\
\hline Observations & 63 & 38 & 38 & 38 & 63 & 63 & 63 \\
\hline $\begin{array}{l}\text { Pseudo R- } \\
\text { squared }\end{array}$ & 0.05 & 0.5 & 0.32 & 0.59 & 0.05 & 0.1 & 0.11 \\
\hline \multicolumn{8}{|c|}{ Standard errors in brackets } \\
\hline * significant a & ${ }^{* *}$ significa & nt at $5 \%$; *** & gnificant at & & & & \\
\hline
\end{tabular}


Table 2

Marginal effects calculated at mean level.

\begin{tabular}{|c|c|c|c|c|c|c|c|}
\hline \multicolumn{8}{|c|}{ Protestants: Marginal Effects } \\
\hline & 1 & II & III & IV & V & VI & VII \\
\hline \multirow[t]{2}{*}{ Mortality } & -0.106 & -0.583 & -0.529 & -0.525 & -0.112 & -0.163 & -0.069 \\
\hline & {$[0.053]^{* *}$} & {$[0.164]^{* * *}$} & {$[0.186]^{* * *}$} & {$[0.162]^{* * *}$} & {$[0.059]^{*}$} & {$[0.061]^{* * *}$} & {$[0.058]$} \\
\hline \multirow[t]{2}{*}{ Pop. Density } & & 0.047 & & 0.088 & & & \\
\hline & & {$[0.023]^{* *}$} & & {$[0.038]^{* *}$} & & & \\
\hline \multirow[t]{2}{*}{ Gold } & & & & & & & 0.027 \\
\hline & & & & & & & [0.116] \\
\hline \multirow[t]{2}{*}{ Iron } & & & & & & & 0.112 \\
\hline & & & & & & & {$[0.171]$} \\
\hline \multirow[t]{2}{*}{ Silver } & & & & & & & -0.057 \\
\hline & & & & & & & {$[0.076]$} \\
\hline \multirow[t]{2}{*}{ Zinc } & & & & & & & 0.023 \\
\hline & & & & & & & {$[0.125]$} \\
\hline \multirow[t]{2}{*}{ Aver. Temp. } & & & & & & 0.03 & \\
\hline & & & & & & {$[0.015]^{* *}$} & \\
\hline \multirow[t]{2}{*}{ Latitude } & & & & & -0.133 & & \\
\hline & & & & & {$[0.551]$} & & \\
\hline \multirow[t]{2}{*}{ Urbanization } & & & -0.002 & -0.062 & & & \\
\hline & & & {$[0.019]$} & {$[0.032]^{*}$} & & & \\
\hline Observations & 63 & 38 & 38 & 38 & 63 & 63 & 63 \\
\hline $\begin{array}{l}\text { Pseudo R- } \\
\text { squared }\end{array}$ & 0.05 & 0.5 & 0.32 & 0.59 & 0.05 & 0.1 & 0.11 \\
\hline \multicolumn{8}{|c|}{ Standard errors in brackets } \\
\hline
\end{tabular}


Table 3

Probit regression: the dependent variable is dummy indicating whether the colonizer was a common law country

\begin{tabular}{|c|c|c|c|c|c|c|c|}
\hline \multicolumn{8}{|c|}{ Common Law: Coefficients } \\
\hline & I & II & III & IV & V & VI & VII \\
\hline \multirow[t]{2}{*}{ Mortality } & -0.276 & -1.967 & -1.967 & -1.916 & -0.273 & -0.384 & -0.155 \\
\hline & {$[0.136]^{* *}$} & {$[0.676]^{* * *}$} & {$[0.736]^{* * *}$} & {$[0.711]^{* * *}$} & {$[0.150]^{*}$} & {$[0.155]^{* *}$} & [0.149] \\
\hline \multirow[t]{2}{*}{ Pop. Density } & & 0.007 & & 0.013 & & & \\
\hline & & [0.013] & & {$[0.015]$} & & & \\
\hline \multirow[t]{2}{*}{ Urbanization } & & & -0.034 & -0.06 & & & \\
\hline & & & {$[0.057]$} & [0.067] & & & \\
\hline \multirow[t]{2}{*}{ Gold } & & & & & & & 0.067 \\
\hline & & & & & & & {$[0.298]$} \\
\hline \multirow[t]{2}{*}{ Iron } & & & & & & & 0.293 \\
\hline & & & & & & & {$[0.437]$} \\
\hline \multirow[t]{2}{*}{ Silver } & & & & & & & -0.142 \\
\hline & & & & & & & [0.199] \\
\hline \multirow[t]{2}{*}{ Zinc } & & & & & & & 0.073 \\
\hline & & & & & & & {$[0.321]$} \\
\hline \multirow[t]{2}{*}{ Aver. Temp. } & & & & & & 0.057 & \\
\hline & & & & & & [0.037] & \\
\hline \multirow[t]{2}{*}{ Latitude } & & & & & 0.06 & & \\
\hline & & & & & [1.430] & & \\
\hline \multirow[t]{2}{*}{ Constant } & 1.001 & 7.558 & 7.863 & 7.674 & 0.978 & 0.204 & 0.333 \\
\hline & {$[0.654]$} & {$[2.861]^{* * *}$} & {$[3.138]^{* *}$} & {$[3.024]^{* *}$} & [0.855] & [0.829] & [0.743] \\
\hline Observations & 59 & 36 & 36 & 36 & 59 & 59 & 59 \\
\hline $\begin{array}{l}\text { Pseudo R- } \\
\text { squared }\end{array}$ & 0.05 & 0.48 & 0.48 & 0.49 & 0.05 & 0.09 & 0.14 \\
\hline \multicolumn{8}{|c|}{ Standard errors in brackets } \\
\hline \multicolumn{7}{|c|}{$*$ significant at $10 \% ; * *$ significant at $5 \% ; * * *$ significant at $1 \%$} & \\
\hline
\end{tabular}


Table 4

Marginal effects calculated at mean level.

\begin{tabular}{|c|c|c|c|c|c|c|c|}
\hline \multicolumn{8}{|c|}{ Common Law: Marginal Effects } \\
\hline & 1 & II & III & IV & V & VI & VII \\
\hline \multirow[t]{2}{*}{ Mortality } & -0.106 & -0.748 & -0.758 & -0.727 & -0.105 & -0.147 & -0.061 \\
\hline & {$[0.052]^{* *}$} & {$[0.293]^{* *}$} & {$[0.318]^{* *}$} & {$[0.309]^{* *}$} & {$[0.058]^{*}$} & {$[0.060]^{* *}$} & [0.059] \\
\hline \multirow[t]{2}{*}{ Pop. Density } & & 0.002 & & 0.005 & & & \\
\hline & & {$[0.005]$} & & {$[0.006]$} & & & \\
\hline \multirow[t]{2}{*}{ Gold } & & & & & & & 0.026 \\
\hline & & & & & & & {$[0.118]$} \\
\hline \multirow[t]{2}{*}{ Iron } & & & & & & & 0.115 \\
\hline & & & & & & & [0.174] \\
\hline \multirow[t]{2}{*}{ Silver } & & & & & & & -0.056 \\
\hline & & & & & & & [0.078] \\
\hline \multirow[t]{2}{*}{ Zinc } & & & & & & & 0.029 \\
\hline & & & & & & & {$[0.126]$} \\
\hline \multirow[t]{2}{*}{ Aver. Temp. } & & & & & & 0.022 & \\
\hline & & & & & & [0.014] & \\
\hline \multirow[t]{2}{*}{ Latitude } & & & & & 0.023 & & \\
\hline & & & & & [0.548] & & \\
\hline \multirow[t]{2}{*}{ Urbanization } & & & -0.013 & -0.023 & & & \\
\hline & & & [0.022] & {$[0.025]$} & & & \\
\hline Observations & 59 & 36 & 36 & 36 & 59 & 59 & 59 \\
\hline $\begin{array}{l}\text { Pseudo R- } \\
\text { squared }\end{array}$ & 0.05 & 0.48 & 0.48 & 0.49 & 0.05 & 0.09 & 0.14 \\
\hline \multicolumn{8}{|c|}{ Standard errors in brackets } \\
\hline * significant at & ; ** significa & t at $5 \% ; * *$ & significant a & $1 \%$ & & & \\
\hline
\end{tabular}


Table 5

Probit regression: the dependent variable is dummy indicating whether the colonizer was England

\begin{tabular}{|c|c|c|c|c|c|c|c|}
\hline \multicolumn{8}{|c|}{ England: Coefficients } \\
\hline & 1 & II & III & IV & V & VI & VII \\
\hline \multirow[t]{2}{*}{ Mortality } & -0.322 & -2.087 & -2.037 & -2.336 & -0.298 & -0.452 & -0.22 \\
\hline & {$[0.135]^{* *}$} & {$[0.601]^{* * *}$} & {$[0.739]^{* * *}$} & {$[0.930]^{* *}$} & {$[0.150]^{* *}$} & {$[0.155]^{* * *}$} & [0.147] \\
\hline \multirow[t]{2}{*}{ Pop. Density } & & 0.133 & & 0.367 & & & \\
\hline & & {$[0.062]^{* *}$} & & {$[0.268]$} & & & \\
\hline \multirow[t]{2}{*}{ Urbanization } & & & 0 & -0.3 & & & \\
\hline & & & [0.052] & {$[0.246]$} & & & \\
\hline \multirow[t]{2}{*}{ Gold } & & & & & & & 0.061 \\
\hline & & & & & & & [0.291] \\
\hline \multirow[t]{2}{*}{ Iron } & & & & & & & 0.274 \\
\hline & & & & & & & [0.437] \\
\hline \multirow[t]{2}{*}{ Silver } & & & & & & & -0.148 \\
\hline & & & & & & & [0.200] \\
\hline \multirow[t]{2}{*}{ Zinc } & & & & & & & 0.078 \\
\hline & & & & & & & {$[0.321]$} \\
\hline \multirow[t]{2}{*}{ Aver. Temp. } & & & & & & 0.07 & \\
\hline & & & & & & {$[0.037]^{*}$} & \\
\hline \multirow[t]{2}{*}{ Latitude } & & & & & 0.526 & & \\
\hline & & & & & [1.418] & & \\
\hline \multirow[t]{2}{*}{ Constant } & 1.223 & 7.391 & 8.023 & 9.048 & 1.014 & 0.227 & 0.668 \\
\hline & {$[0.645]^{*}$} & {$[2.446]^{* * *}$} & {$[3.161]^{* *}$} & {$[3.843]^{* *}$} & [0.853] & {$[0.831]$} & {$[0.722]$} \\
\hline Observations & 63 & 38 & 38 & 38 & 63 & 63 & 63 \\
\hline $\begin{array}{l}\text { Pseudo R- } \\
\text { squared }\end{array}$ & 0.07 & 0.67 & 0.45 & 0.78 & 0.07 & 0.11 & 0.14 \\
\hline \multicolumn{8}{|c|}{ Standard errors in brackets } \\
\hline
\end{tabular}


Table 6

Marginal effects calculated at mean level.

\begin{tabular}{|c|c|c|c|c|c|c|c|}
\hline \multicolumn{8}{|c|}{ England: Marginal Effects } \\
\hline & 1 & II & III & IV & V & VI & VII \\
\hline \multirow[t]{2}{*}{ Mortality } & -0.124 & -0.82 & -0.791 & -0.925 & -0.115 & -0.174 & -0.087 \\
\hline & {$[0.052]^{* *}$} & {$[0.253]^{* * *}$} & {$[0.317]^{* *}$} & {$[0.349]^{* * *}$} & {$[0.058]^{* *}$} & {$[0.060]^{* * *}$} & {$[0.058]$} \\
\hline \multirow[t]{2}{*}{ Pop. Density } & & 0.052 & & 0.145 & & & \\
\hline & & {$[0.026]^{* *}$} & & [0.100] & & & \\
\hline \multirow[t]{2}{*}{ Gold } & & & & & & & 0.024 \\
\hline & & & & & & & {$[0.115]$} \\
\hline \multirow[t]{2}{*}{ Iron } & & & & & & & 0.108 \\
\hline & & & & & & & {$[0.173]$} \\
\hline \multirow[t]{2}{*}{ Silver } & & & & & & & -0.058 \\
\hline & & & & & & & {$[0.078]$} \\
\hline \multirow[t]{2}{*}{ Zinc } & & & & & & & 0.031 \\
\hline & & & & & & & {$[0.126]$} \\
\hline \multirow[t]{2}{*}{ Aver. Temp. } & & & & & & 0.027 & \\
\hline & & & & & & {$[0.014]^{*}$} & \\
\hline \multirow[t]{2}{*}{ Latitude } & & & & & 0.202 & & \\
\hline & & & & & {$[0.546]$} & & \\
\hline \multirow[t]{2}{*}{ Urbanization } & & & 0 & -0.119 & & & \\
\hline & & & {$[0.020]$} & {$[0.095]$} & & & \\
\hline Observations & 63 & 38 & 38 & 38 & 63 & 63 & 63 \\
\hline $\begin{array}{l}\text { Pseudo R- } \\
\text { squared }\end{array}$ & 0.07 & 0.67 & 0.45 & 0.78 & 0.07 & 0.11 & 0.14 \\
\hline \multicolumn{8}{|c|}{ Standard errors in brackets } \\
\hline * significant at & ** significa & nt at $5 \% ; * * *$ & ignificant at & $1 \%$ & & & \\
\hline
\end{tabular}


Table 7

Probit regression: the dependent variable is dummy indicating whether the colonizer was France

\begin{tabular}{|c|c|c|c|c|c|c|c|}
\hline \multicolumn{8}{|c|}{ France: Coefficients } \\
\hline & I & II & III & IV & V & VI & VII \\
\hline \multirow[t]{2}{*}{ Mortality } & 0.528 & 1.134 & 1.417 & 1.349 & 0.757 & 0.416 & 0.477 \\
\hline & {$[0.169]^{* * *}$} & {$[0.680]^{*}$} & {$[0.825]^{*}$} & {$[0.834]$} & {$[0.218]^{* * *}$} & {$[0.179]^{* *}$} & {$[0.175]^{* * *}$} \\
\hline \multirow[t]{2}{*}{ Pop. Density } & & 0 & & -0.009 & & & \\
\hline & & [0.017] & & {$[0.020]$} & & & \\
\hline \multirow[t]{2}{*}{ Urbanization } & & & 0.097 & 0.105 & & & \\
\hline & & & {$[0.068]$} & {$[0.070]$} & & & \\
\hline \multirow[t]{2}{*}{ Aver. Temp. } & & & & & & 0.086 & \\
\hline & & & & & & {$[0.058]$} & \\
\hline \multirow[t]{2}{*}{ Latitude } & & & & & 4.073 & & \\
\hline & & & & & {$[1.952]^{* *}$} & & \\
\hline \multirow[t]{2}{*}{ Constant } & -3.304 & -5.918 & -8 & -7.699 & -5.199 & -4.829 & -2.959 \\
\hline & {$[0.876]^{* * *}$} & {$[3.080]^{*}$} & {$[4.007]^{* *}$} & {$[4.041]^{*}$} & {$[1.383]^{* * *}$} & {$[1.466]^{* * *}$} & {$[0.915]^{* * *}$} \\
\hline Observations & 63 & 38 & 38 & 38 & 63 & 63 & 53 \\
\hline $\begin{array}{l}\text { Pseudo R- } \\
\text { squared }\end{array}$ & 0.17 & 0.15 & 0.22 & 0.23 & 0.23 & 0.2 & 0.13 \\
\hline \multicolumn{8}{|c|}{ Standard errors in brackets } \\
\hline \multicolumn{8}{|c|}{$*$ significant at $10 \% ; * *$ significant at $5 \% ; * * *$ significant at $1 \%$} \\
\hline
\end{tabular}


Table 8

Marginal effects calculated at mean.

\begin{tabular}{|c|c|c|c|c|c|c|c|}
\hline \multicolumn{8}{|c|}{ France: Marginal Effects } \\
\hline & 1 & II & III & IV & V & VI & VII \\
\hline \multirow[t]{2}{*}{ Mortality } & 0.146 & 0.189 & 0.147 & 0.145 & 0.194 & 0.108 & 0.152 \\
\hline & {$[0.044]^{* * *}$} & {$[0.079]^{* *}$} & {$[0.082]^{*}$} & {$[0.078]^{*}$} & {$[0.052]^{* * *}$} & {$[0.047]^{* *}$} & {$[0.054]^{* * *}$} \\
\hline \multirow[t]{2}{*}{ Pop. Density } & & 0 & & -0.001 & & & \\
\hline & & [0.003] & & [0.002] & & & \\
\hline \multirow[t]{2}{*}{ Aver. Temp. } & & & & & & 0.022 & \\
\hline & & & & & & [0.014] & \\
\hline \multirow[t]{2}{*}{ Latitude } & & & & & 1.042 & & \\
\hline & & & & & {$[0.473]^{* *}$} & & \\
\hline \multirow[t]{2}{*}{ Urbanization } & & & 0.01 & 0.011 & & & \\
\hline & & & [0.008] & [0.009] & & & \\
\hline Observations & 63 & 38 & 38 & 38 & 63 & 63 & 53 \\
\hline $\begin{array}{l}\text { Pseudo R- } \\
\text { squared }\end{array}$ & 0.17 & 0.15 & 0.22 & 0.23 & 0.23 & 0.2 & 0.13 \\
\hline \multicolumn{8}{|c|}{ Standard errors in brackets } \\
\hline
\end{tabular}


Table 9

Probit regression: the dependent variable is dummy indicating whether the colonizer was Spain

\begin{tabular}{|c|c|c|c|c|c|c|c|}
\hline \multicolumn{8}{|c|}{ Spain: Coefficients } \\
\hline & 1 & II & III & IV & V & VI & VII \\
\hline \multirow[t]{2}{*}{ Mortality } & -0.143 & 1.378 & 0.814 & 2.088 & -0.186 & 0.136 & -0.255 \\
\hline & {$[0.152]$} & {$[0.467]^{* * *}$} & {$[0.370]^{* *}$} & {$[0.851]^{* *}$} & {$[0.170]$} & {$[0.183]$} & {$[0.179]$} \\
\hline \multirow[t]{2}{*}{ Pop. Density } & & -0.534 & & -2.148 & & & \\
\hline & & {$[0.233]^{* *}$} & & {$[1.286]^{*}$} & & & \\
\hline \multirow[t]{2}{*}{ Urbanization } & & & -0.01 & 0.43 & & & \\
\hline & & & {$[0.044]$} & {$[0.207]^{* *}$} & & & \\
\hline \multirow[t]{2}{*}{ Aver. Temp. } & & & & & & -0.132 & \\
\hline & & & & & & {$[0.040]^{* * *}$} & \\
\hline \multirow[t]{2}{*}{ Latitude } & & & & & -0.867 & & \\
\hline & & & & & {$[1.470]$} & & \\
\hline \multirow[t]{2}{*}{ Constant } & -0.013 & -4.846 & -3.515 & -7.971 & 0.344 & 1.601 & 0.497 \\
\hline & {$[0.702]$} & {$[1.823]^{* * *}$} & {$[1.563]^{* *}$} & {$[3.219]^{* *}$} & {$[0.927]$} & {$[0.857]^{*}$} & {$[0.840]$} \\
\hline Observations & 63 & 38 & 38 & 38 & 63 & 63 & 53 \\
\hline $\begin{array}{l}\text { Pseudo R- } \\
\text { squared }\end{array}$ & 0.01 & 0.44 & 0.12 & 0.69 & 0.02 & 0.18 & 0.04 \\
\hline \multicolumn{8}{|c|}{ Standard errors in brackets } \\
\hline \multicolumn{8}{|c|}{$*$ significant at $10 \% ; * *$ significant at $5 \% ; * * *$ significant at $1 \%$} \\
\hline
\end{tabular}


Table 10

Marginal effect calculated at mean

\begin{tabular}{|c|c|c|c|c|c|c|c|}
\hline \multicolumn{8}{|c|}{ Spain: Marginal Effects } \\
\hline & I & II & III & IV & V & VI & VII \\
\hline \multirow[t]{2}{*}{ Mortality } & -0.045 & 0.01 & 0.312 & 0 & -0.059 & 0.04 & -0.078 \\
\hline & {$[0.048]$} & {$[0.035]$} & {$[0.137]^{* *}$} & {$[0.000]$} & {$[0.053]$} & {$[0.054]$} & {$[0.054]$} \\
\hline \multirow[t]{2}{*}{ Pop. Density } & & -0.004 & & 0 & & & \\
\hline & & [0.012] & & {$[0.000]$} & & & \\
\hline \multirow[t]{2}{*}{ Aver. Temp. } & & & & & & -0.039 & \\
\hline & & & & & & {$[0.012]^{* * *}$} & \\
\hline \multirow[t]{2}{*}{ Latitude } & & & & & -0.275 & & \\
\hline & & & & & [0.465] & & \\
\hline \multirow[t]{2}{*}{ Urbanization } & & & -0.004 & 0 & & & \\
\hline & & & [0.017] & {$[0.000]$} & & & \\
\hline Observations & 63 & 38 & 38 & 38 & 63 & 63 & 53 \\
\hline $\begin{array}{l}\text { Pseudo R- } \\
\text { squared }\end{array}$ & 0.01 & 0.44 & 0.12 & 0.69 & 0.02 & 0.18 & 0.04 \\
\hline \multicolumn{8}{|c|}{ Standard errors in brackets } \\
\hline \multicolumn{8}{|c|}{$*$ significant at $10 \% ;{ }^{* *}$ significant at $5 \% ; * * *$ significant at $1 \%$} \\
\hline
\end{tabular}


Table 11

Probit regression: the dependent variable is dummy indicating whether the colonizer was a protestant country. Sample restricted to the colonies colonized before 1896.

\begin{tabular}{|c|c|c|c|c|c|c|c|}
\hline \multicolumn{8}{|c|}{ Protestants, Subsample 1: Coefficients } \\
\hline & 1 & II & III & IV & V & VI & VII \\
\hline \multirow[t]{2}{*}{ Mortality } & -0.261 & -1.459 & -1.359 & -1.366 & -0.272 & -0.393 & -0.144 \\
\hline & {$[0.153]^{*}$} & {$[0.413]^{* * *}$} & {$[0.448]^{* * *}$} & {$[0.436]^{* * *}$} & {$[0.174]$} & {$[0.172]^{* *}$} & {$[0.170]$} \\
\hline \multirow[t]{2}{*}{ Pop. Density } & & 0.131 & & 0.228 & & & \\
\hline & & {$[0.066]^{* *}$} & & {$[0.118]^{*}$} & & & \\
\hline \multirow[t]{2}{*}{ Urbanization } & & & 0.007 & -0.149 & & & \\
\hline & & & {$[0.052]$} & {$[0.090]^{*}$} & & & \\
\hline \multirow[t]{2}{*}{ Gold } & & & & & & & 0.073 \\
\hline & & & & & & & {$[0.290]$} \\
\hline \multirow[t]{2}{*}{ Iron } & & & & & & & 0.288 \\
\hline & & & & & & & {$[0.424]$} \\
\hline \multirow[t]{2}{*}{ Silver } & & & & & & & -0.14 \\
\hline & & & & & & & {$[0.189]$} \\
\hline \multirow[t]{2}{*}{ Zinc } & & & & & & & 0.048 \\
\hline & & & & & & & {$[0.310]$} \\
\hline \multirow[t]{2}{*}{ Aver. Temp. } & & & & & & 0.078 & \\
\hline & & & & & & {$[0.038]^{* *}$} & \\
\hline \multirow[t]{2}{*}{ Latitude } & & & & & -0.198 & & \\
\hline & & & & & [1.470] & & \\
\hline \multirow[t]{2}{*}{ Constant } & 1.123 & 5.114 & 5.287 & 5.253 & 1.21 & -0.007 & 0.515 \\
\hline & {$[0.714]$} & {$[1.687]^{* * *}$} & {$[1.882]^{* * *}$} & {$[1.785]^{* * *}$} & {$[0.962]$} & [0.899] & [0.815] \\
\hline Observations & 54 & 37 & 37 & 37 & 54 & 54 & 54 \\
\hline $\begin{array}{l}\text { Pseudo R- } \\
\text { squared }\end{array}$ & 0.04 & 0.52 & 0.32 & 0.59 & 0.04 & 0.1 & 0.11 \\
\hline \multicolumn{8}{|c|}{ Standard errors in brackets } \\
\hline * significant at & ;* signifi & ant at $5 \% ; * * *$ & significant at & & & & \\
\hline
\end{tabular}


Table 12

\begin{tabular}{|c|c|c|c|c|c|c|c|}
\hline \multicolumn{8}{|c|}{ Protestants, Subsample 1: Marginal Effects } \\
\hline & 1 & II & III & IV & V & VI & VII \\
\hline \multirow[t]{2}{*}{ Mortality } & -0.104 & -0.58 & -0.534 & -0.516 & -0.108 & -0.157 & -0.057 \\
\hline & {$[0.061]^{*}$} & {$[0.160]^{* * *}$} & {$[0.184]^{* * *}$} & {$[0.162]^{* * *}$} & {$[0.069]$} & {$[0.068]^{* *}$} & [0.068] \\
\hline \multirow[t]{2}{*}{ Pop. Density } & & 0.052 & & 0.086 & & & \\
\hline & & {$[0.025]^{* *}$} & & {$[0.035]^{* *}$} & & & \\
\hline \multirow[t]{2}{*}{ Gold } & & & & & & & 0.029 \\
\hline & & & & & & & [0.115] \\
\hline \multirow[t]{2}{*}{ Iron } & & & & & & & 0.114 \\
\hline & & & & & & & [0.168] \\
\hline \multirow[t]{2}{*}{ Silver } & & & & & & & -0.056 \\
\hline & & & & & & & [0.075] \\
\hline \multirow[t]{2}{*}{ Zinc } & & & & & & & 0.019 \\
\hline & & & & & & & [0.123] \\
\hline \multirow[t]{2}{*}{ Aver. Temp. } & & & & & & 0.031 & \\
\hline & & & & & & {$[0.015]^{* *}$} & \\
\hline \multirow[t]{2}{*}{ Latitude } & & & & & -0.079 & & \\
\hline & & & & & [0.586] & & \\
\hline \multirow[t]{2}{*}{ Urbanization } & & & 0.003 & -0.056 & & & \\
\hline & & & [0.020] & {$[0.032]^{*}$} & & & \\
\hline Observations & 54 & 37 & 37 & 37 & 54 & 54 & 54 \\
\hline $\begin{array}{l}\text { Pseudo R- } \\
\text { squared }\end{array}$ & 0.04 & 0.52 & 0.32 & 0.59 & 0.04 & 0.1 & 0.11 \\
\hline \multicolumn{8}{|c|}{ Standard errors in brackets } \\
\hline
\end{tabular}


Table 13

Probit regression: the dependent variable is dummy indicating whether the colonizer was a protestant country. Sample restricted to the colonies colonized between 1530 and 1898.

\begin{tabular}{|c|c|c|c|c|c|c|c|}
\hline \multicolumn{8}{|c|}{ Protestants, Subsample 2: Coefficients } \\
\hline & 1 & II & III & IV & V & VI & VII \\
\hline \multirow[t]{2}{*}{ Mortality } & -0.321 & -1.382 & -1.25 & -1.28 & -0.346 & -0.436 & -0.234 \\
\hline & {$[0.147]^{* *}$} & {$[0.423]^{* * *}$} & {$[0.467]^{* * *}$} & {$[0.448]^{* * *}$} & {$[0.166]^{* *}$} & {$[0.167]^{* * *}$} & {$[0.161]$} \\
\hline \multirow[t]{2}{*}{ Pop. Density } & & 0.116 & & 0.21 & & & \\
\hline & & {$[0.063]^{*}$} & & {$[0.117]^{*}$} & & & \\
\hline \multirow[t]{2}{*}{ Urbanization } & & & -0.007 & -0.161 & & & \\
\hline & & & {$[0.055]$} & {$[0.094]^{*}$} & & & \\
\hline \multirow[t]{2}{*}{ Gold } & & & & & & & -0.644 \\
\hline & & & & & & & {$[178.647]$} \\
\hline \multirow[t]{2}{*}{ Iron } & & & & & & & 11.691 \\
\hline & & & & & & & {$[2,239.395]$} \\
\hline \multirow[t]{2}{*}{ Silver } & & & & & & & 1.23 \\
\hline & & & & & & & {$[449.655]$} \\
\hline \multirow[t]{2}{*}{ Zinc } & & & & & & & -5.486 \\
\hline & & & & & & & {$[1,203.411]$} \\
\hline \multirow[t]{2}{*}{ Aver. Temp. } & & & & & & 0.067 & \\
\hline & & & & & & {$[0.041]$} & \\
\hline \multirow[t]{2}{*}{ Latitude } & & & & & -0.491 & & \\
\hline & & & & & {$[1.526]$} & & \\
\hline \multirow[t]{2}{*}{ Constant } & 1.507 & 4.955 & 5.079 & 5.132 & 1.71 & 0.511 & 1.124 \\
\hline & {$[0.706]^{* *}$} & {$[1.722]^{* * *}$} & {$[1.967]^{* * *}$} & {$[1.836]^{* * *}$} & {$[0.951]^{*}$} & {$[0.916]$} & {$[0.801]$} \\
\hline Observations & 51 & 31 & 31 & 31 & 51 & 51 & 51 \\
\hline $\begin{array}{l}\text { Pseudo R- } \\
\text { squared }\end{array}$ & 0.07 & 0.47 & 0.28 & 0.56 & 0.07 & 0.11 & 0.21 \\
\hline \multicolumn{8}{|c|}{ Standard errors in brackets } \\
\hline \multicolumn{7}{|c|}{$*$ significant at $10 \% ; * *$ significant at $5 \% ; * * *$ significant at $1 \%$} & \\
\hline
\end{tabular}


Table 14

\begin{tabular}{|c|c|c|c|c|c|c|c|}
\hline \multicolumn{8}{|c|}{ Protestants, Subsample 2: Marginal Effects } \\
\hline & I & II & III & IV & V & VI & VII \\
\hline \multirow[t]{2}{*}{ Mortality } & -0.128 & -0.509 & -0.496 & -0.392 & -0.138 & -0.174 & -0.003 \\
\hline & {$[0.058]^{* *}$} & {$[0.149]^{* * *}$} & {$[0.180]^{* * *}$} & {$[0.179]^{* *}$} & {$[0.066]^{* *}$} & {$[0.066]^{* * *}$} & [4.221] \\
\hline \multirow[t]{2}{*}{ Pop. Density } & & 0.043 & & 0.064 & & & \\
\hline & & {$[0.019]^{* *}$} & & {$[0.020]^{* * *}$} & & & \\
\hline \multirow[t]{2}{*}{ Gold } & & & & & & & -0.009 \\
\hline & & & & & & & [10.209] \\
\hline \multirow[t]{2}{*}{ Iron } & & & & & & & 0.159 \\
\hline & & & & & & & [184.574] \\
\hline \multirow[t]{2}{*}{ Silver } & & & & & & & 0.017 \\
\hline & & & & & & & [19.604] \\
\hline \multirow[t]{2}{*}{ Zinc } & & & & & & & -0.075 \\
\hline & & & & & & & [87.669] \\
\hline \multirow[t]{2}{*}{ Aver. Temp. } & & & & & & 0.027 & \\
\hline & & & & & & {$[0.016]$} & \\
\hline \multirow[t]{2}{*}{ Latitude } & & & & & -0.196 & & \\
\hline & & & & & [0.609] & & \\
\hline \multirow[t]{2}{*}{ Urbanization } & & & -0.003 & -0.049 & & & \\
\hline & & & [0.022] & {$[0.029]^{*}$} & & & \\
\hline Observations & 51 & 31 & 31 & 31 & 51 & 51 & 51 \\
\hline $\begin{array}{l}\text { Pseudo R- } \\
\text { squared }\end{array}$ & 0.07 & 0.47 & 0.28 & 0.56 & 0.07 & 0.11 & 0.21 \\
\hline \multicolumn{8}{|c|}{ Standard errors in brackets } \\
\hline
\end{tabular}


Table 15

Probit regression: the dependent variable is dummy indicating whether the colonizer was a protestant country. Sample restricted to the colonies colonized after 1533.

\begin{tabular}{|c|c|c|c|c|c|c|c|}
\hline \multicolumn{8}{|c|}{ Protestants, Subsample 3: Coefficients } \\
\hline & 1 & II & III & IV & V & VI & VII \\
\hline \multirow{2}{*}{ Mortality } & -0.29 & -1.356 & -1.244 & -1.266 & -0.311 & -0.407 & -0.201 \\
\hline & {$[0.136]^{* *}$} & {$[0.423]^{* * *}$} & {$[0.472]^{* * *}$} & {$[0.448]^{* * *}$} & {$[0.152]^{* *}$} & {$[0.158]^{* *}$} & {$[0.149]$} \\
\hline \multirow[t]{2}{*}{ Pop. Density } & & 0.098 & & 0.202 & & & \\
\hline & & {$[0.054]^{*}$} & & {$[0.118]^{*}$} & & & \\
\hline \multirow[t]{2}{*}{ Urbanization } & & & -0.006 & -0.162 & & & \\
\hline & & & {$[0.053]$} & {$[0.093]^{*}$} & & & \\
\hline \multirow[t]{2}{*}{ Gold } & & & & & & & -0.433 \\
\hline & & & & & & & {$[0.000]$} \\
\hline \multirow[t]{2}{*}{ Iron } & & & & & & & 9.791 \\
\hline & & & & & & & {$[3,595.179]$} \\
\hline \multirow[t]{2}{*}{ Silver } & & & & & & & 2.627 \\
\hline & & & & & & & {$[1,662.405]$} \\
\hline \multirow[t]{2}{*}{ Zinc } & & & & & & & -5.947 \\
\hline & & & & & & & {$[2,847.982]$} \\
\hline \multirow[t]{2}{*}{ Aver. Temp. } & & & & & & 0.065 & \\
\hline & & & & & & {$[0.040]$} & \\
\hline \multirow[t]{2}{*}{ Latitude } & & & & & -0.439 & & \\
\hline & & & & & {$[1.459]$} & & \\
\hline \multirow[t]{2}{*}{ Constant } & 1.383 & 4.92 & 5.092 & 5.106 & 1.556 & 0.435 & 0.947 \\
\hline & {$[0.666]^{* *}$} & {$[1.730]^{* * *}$} & {$[1.992]^{* *}$} & {$[1.840]^{* * *}$} & {$[0.884]^{*}$} & {$[0.877]$} & {$[0.746]$} \\
\hline Observations & 55 & 30 & 30 & 30 & 55 & 55 & 55 \\
\hline $\begin{array}{l}\text { Pseudo R- } \\
\text { squared }\end{array}$ & 0.06 & 0.45 & 0.29 & 0.55 & 0.06 & 0.1 & 0.17 \\
\hline \multicolumn{8}{|c|}{ Standard errors in brackets } \\
\hline * significant a & $\% ; * *$ signific & nt at $5 \% ; * * *$ & ignificant at & & & & \\
\hline
\end{tabular}


Table 16

\begin{tabular}{|c|c|c|c|c|c|c|c|}
\hline \multicolumn{8}{|c|}{ Protestants, Subsample 3: Marginal Effects } \\
\hline & 1 & II & III & IV & V & VI & VII \\
\hline \multirow[t]{2}{*}{ Mortality } & -0.116 & -0.502 & -0.49 & -0.371 & -0.124 & -0.162 & -0.011 \\
\hline & {$[0.054]^{* *}$} & {$[0.148]^{* * *}$} & {$[0.177]^{* * *}$} & {$[0.186]^{* *}$} & {$[0.061]^{* *}$} & {$[0.063]^{* * *}$} & [17.280] \\
\hline \multirow[t]{2}{*}{ Pop. Density } & & 0.036 & & 0.059 & & & \\
\hline & & {$[0.017]^{* *}$} & & {$[0.019]^{* * *}$} & & & \\
\hline \multirow[t]{2}{*}{ Gold } & & & & & & & -0.023 \\
\hline & & & & & & & [37.289] \\
\hline \multirow[t]{2}{*}{ Iron } & & & & & & & 0.525 \\
\hline & & & & & & & [688.488] \\
\hline \multirow[t]{2}{*}{ Silver } & & & & & & & 0.141 \\
\hline & & & & & & & [201.680] \\
\hline \multirow[t]{2}{*}{ Zinc } & & & & & & & -0.319 \\
\hline & & & & & & & [433.364] \\
\hline \multirow[t]{2}{*}{ Aver. Temp. } & & & & & & 0.026 & \\
\hline & & & & & & {$[0.016]$} & \\
\hline \multirow[t]{2}{*}{ Latitude } & & & & & -0.175 & & \\
\hline & & & & & {$[0.582]$} & & \\
\hline \multirow[t]{2}{*}{ Urbanization } & & & -0.002 & -0.048 & & & \\
\hline & & & [0.021] & {$[0.027]^{*}$} & & & \\
\hline Observations & 55 & 30 & 30 & 30 & 55 & 55 & 55 \\
\hline $\begin{array}{l}\text { Pseudo R- } \\
\text { squared }\end{array}$ & 0.06 & 0.45 & 0.29 & 0.55 & 0.06 & 0.1 & 0.17 \\
\hline \multicolumn{8}{|c|}{ Standard errors in brackets } \\
\hline
\end{tabular}


Table 17

Probit regression: the dependent variable is dummy indicating whether the colonizer was a common law country. Sample restricted to the colonies colonized before 1896.

\begin{tabular}{|c|c|c|c|c|c|c|c|}
\hline \multicolumn{8}{|c|}{ Common Law, Subsample 1: Coefficients } \\
\hline & 1 & II & III & IV & V & VI & VII \\
\hline \multirow[t]{2}{*}{ Mortality } & -0.287 & -1.944 & -1.953 & -1.909 & -0.276 & -0.379 & -0.143 \\
\hline & {$[0.155]^{*}$} & {$[0.673]^{* * *}$} & {$[0.724]^{* * *}$} & {$[0.706]^{* * *}$} & [0.174] & {$[0.171]^{* *}$} & [0.174] \\
\hline \multirow[t]{2}{*}{ Pop. Density } & & 0.006 & & 0.012 & & & \\
\hline & & [0.013] & & [0.015] & & & \\
\hline \multirow[t]{2}{*}{ Urbanization } & & & -0.027 & -0.053 & & & \\
\hline & & & {$[0.061]$} & {$[0.071]$} & & & \\
\hline \multirow[t]{2}{*}{ Gold } & & & & & & & 0.069 \\
\hline & & & & & & & [0.298] \\
\hline \multirow[t]{2}{*}{ Iron } & & & & & & & 0.294 \\
\hline & & & & & & & [0.435] \\
\hline \multirow[t]{2}{*}{ Silver } & & & & & & & -0.14 \\
\hline & & & & & & & {$[0.197]$} \\
\hline \multirow[t]{2}{*}{ Zinc } & & & & & & & 0.067 \\
\hline & & & & & & & {$[0.319]$} \\
\hline \multirow[t]{2}{*}{ Aver. Temp. } & & & & & & 0.055 & \\
\hline & & & & & & {$[0.038]$} & \\
\hline \multirow[t]{2}{*}{ Latitude } & & & & & 0.219 & & \\
\hline & & & & & {$[1.506]$} & & \\
\hline \multirow[t]{2}{*}{ Constant } & 1.088 & 7.489 & 7.769 & 7.622 & 0.997 & 0.28 & 0.319 \\
\hline & {$[0.726]$} & {$[2.848]^{* * *}$} & {$[3.092]^{* *}$} & {$[3.003]^{* *}$} & {$[0.957]$} & {$[0.910]$} & {$[0.842]$} \\
\hline Observations & 50 & 35 & 35 & 35 & 50 & 50 & 50 \\
\hline $\begin{array}{l}\text { Pseudo R- } \\
\text { squared }\end{array}$ & 0.05 & 0.47 & 0.47 & 0.49 & 0.05 & 0.08 & 0.14 \\
\hline \multicolumn{8}{|c|}{ Standard errors in brackets } \\
\hline \multicolumn{8}{|c|}{$*$ significant at $10 \% ; * *$ significant at $5 \% ; * * *$ significant at $1 \%$} \\
\hline
\end{tabular}


Table 18

\begin{tabular}{|c|c|c|c|c|c|c|c|}
\hline \multicolumn{8}{|c|}{ Common Law, Subsample 1: Marginal Effects } \\
\hline & I & II & III & IV & V & VI & VII \\
\hline \multirow[t]{2}{*}{ Mortality } & -0.112 & -0.748 & -0.76 & -0.734 & -0.108 & -0.148 & -0.057 \\
\hline & {$[0.061]^{*}$} & {$[0.290]^{* * *}$} & {$[0.311]^{* *}$} & {$[0.305]^{* *}$} & {$[0.068]$} & {$[0.067]^{* *}$} & [0.069] \\
\hline \multirow[t]{2}{*}{ Pop. Density } & & 0.002 & & 0.005 & & & \\
\hline & & [0.005] & & [0.006] & & & \\
\hline \multirow[t]{2}{*}{ Gold } & & & & & & & 0.028 \\
\hline & & & & & & & [0.119] \\
\hline \multirow[t]{2}{*}{ Iron } & & & & & & & 0.117 \\
\hline & & & & & & & [0.174] \\
\hline \multirow[t]{2}{*}{ Silver } & & & & & & & -0.056 \\
\hline & & & & & & & [0.078] \\
\hline \multirow[t]{2}{*}{ Zinc } & & & & & & & 0.027 \\
\hline & & & & & & & [0.127] \\
\hline \multirow[t]{2}{*}{ Aver. Temp. } & & & & & & 0.022 & \\
\hline & & & & & & [0.015] & \\
\hline \multirow[t]{2}{*}{ Latitude } & & & & & 0.086 & & \\
\hline & & & & & [0.589] & & \\
\hline \multirow[t]{2}{*}{ Urbanization } & & & -0.01 & -0.02 & & & \\
\hline & & & [0.024] & [0.027] & & & \\
\hline Observations & 50 & 35 & 35 & 35 & 50 & 50 & 50 \\
\hline $\begin{array}{l}\text { Pseudo R- } \\
\text { squared }\end{array}$ & 0.05 & 0.47 & 0.47 & 0.49 & 0.05 & 0.08 & 0.14 \\
\hline \multicolumn{8}{|c|}{ Standard errors in brackets } \\
\hline
\end{tabular}


Table 19

Probit regression: the dependent variable is dummy indicating whether the colonizer was a common law country. Sample restricted to the colonies colonized between 1530 and 1896.

\begin{tabular}{|c|c|c|c|c|c|c|c|}
\hline \multicolumn{8}{|c|}{ Common Law, Subsample 2: Coefficients } \\
\hline & 1 & II & III & IV & V & VI & VII \\
\hline \multirow[t]{2}{*}{ Mortality } & -0.337 & -1.848 & -1.847 & -1.814 & -0.335 & -0.409 & -0.225 \\
\hline & {$[0.149]^{* *}$} & {$[0.689]^{* * *}$} & {$[0.755]^{* *}$} & {$[0.737]^{* *}$} & {$[0.166]^{* *}$} & {$[0.166]^{* *}$} & {$[0.165]$} \\
\hline \multirow[t]{2}{*}{ Pop. Density } & & 0.004 & & 0.011 & & & \\
\hline & & {$[0.013]$} & & {$[0.015]$} & & & \\
\hline \multirow[t]{2}{*}{ Urbanization } & & & -0.044 & -0.069 & & & \\
\hline & & & {$[0.065]$} & {$[0.076]$} & & & \\
\hline \multirow[t]{2}{*}{ Gold } & & & & & & & -0.616 \\
\hline & & & & & & & [170.605] \\
\hline \multirow[t]{2}{*}{ Iron } & & & & & & & 11.313 \\
\hline & & & & & & & {$[2,084.356]$} \\
\hline \multirow[t]{2}{*}{ Silver } & & & & & & & 1.184 \\
\hline & & & & & & & [420.846] \\
\hline \multirow[t]{2}{*}{ Zinc } & & & & & & & -5.28 \\
\hline & & & & & & & {$[1,121.119]$} \\
\hline \multirow[t]{2}{*}{ Aver. Temp. } & & & & & & 0.044 & \\
\hline & & & & & & {$[0.041]$} & \\
\hline \multirow[t]{2}{*}{ Latitude } & & & & & 0.043 & & \\
\hline & & & & & {$[1.561]$} & & \\
\hline \multirow[t]{2}{*}{ Constant } & 1.423 & 7.247 & 7.591 & 7.487 & 1.406 & 0.771 & 0.889 \\
\hline & {$[0.719]^{* *}$} & {$[2.909]^{* *}$} & {$[3.238]^{* *}$} & {$[3.150]^{* *}$} & {$[0.945]$} & [0.934] & {$[0.827]$} \\
\hline Observations & 47 & 29 & 29 & 29 & 47 & 47 & 47 \\
\hline $\begin{array}{l}\text { Pseudo R- } \\
\text { squared }\end{array}$ & 0.08 & 0.44 & 0.45 & 0.46 & 0.08 & 0.1 & 0.23 \\
\hline \multicolumn{8}{|c|}{ Standard errors in brackets } \\
\hline \multicolumn{8}{|c|}{$*$ significant at $10 \% ; * *$ significant at $5 \% ; * * *$ significant at $1 \%$} \\
\hline
\end{tabular}


Table 20

\begin{tabular}{|c|c|c|c|c|c|c|c|}
\hline \multicolumn{8}{|c|}{ Common Law, Subsample 2: Marginal Effects } \\
\hline & I & II & III & IV & V & VI & VII \\
\hline \multirow[t]{2}{*}{ Mortality } & -0.133 & -0.735 & -0.731 & -0.72 & -0.133 & -0.162 & -0.003 \\
\hline & {$[0.059]^{* *}$} & {$[0.263]^{* * *}$} & {$[0.277]^{* * *}$} & {$[0.277]^{* * *}$} & {$[0.066]^{* *}$} & {$[0.066]^{* *}$} & [4.452] \\
\hline \multirow[t]{2}{*}{ Pop. Density } & & 0.001 & & 0.004 & & & \\
\hline & & {$[0.005]$} & & {$[0.006]$} & & & \\
\hline \multirow[t]{2}{*}{ Gold } & & & & & & & -0.009 \\
\hline & & & & & & & [10.814] \\
\hline \multirow[t]{2}{*}{ Iron } & & & & & & & 0.169 \\
\hline & & & & & & & [197.335] \\
\hline \multirow[t]{2}{*}{ Silver } & & & & & & & 0.018 \\
\hline & & & & & & & [20.831] \\
\hline \multirow[t]{2}{*}{ Zinc } & & & & & & & -0.079 \\
\hline & & & & & & & [93.164] \\
\hline \multirow[t]{2}{*}{ Aver. Temp. } & & & & & & 0.017 & \\
\hline & & & & & & [0.016] & \\
\hline \multirow[t]{2}{*}{ Latitude } & & & & & 0.017 & & \\
\hline & & & & & [0.617] & & \\
\hline \multirow[t]{2}{*}{ Urbanization } & & & -0.018 & -0.028 & & & \\
\hline & & & [0.026] & [0.030] & & & \\
\hline Observations & 47 & 29 & 29 & 29 & 47 & 47 & 47 \\
\hline $\begin{array}{l}\text { Pseudo R- } \\
\text { squared }\end{array}$ & 0.08 & 0.44 & 0.45 & 0.46 & 0.08 & 0.1 & 0.23 \\
\hline \multicolumn{8}{|c|}{ Standard errors in brackets } \\
\hline
\end{tabular}


Table 21

Probit regression: the dependent variable is dummy indicating whether the colonizer was a common law country. Sample restricted to the colonies colonized after 1533

\begin{tabular}{|c|c|c|c|c|c|c|c|}
\hline \multicolumn{8}{|c|}{ Common Law, Subsample 3: Coefficients } \\
\hline & I & II & III & IV & V & VI & VII \\
\hline \multirow[t]{2}{*}{ Mortality } & -0.297 & -1.835 & -1.827 & -1.798 & -0.295 & -0.376 & -0.185 \\
\hline & {$[0.138]^{* *}$} & {$[0.698]^{* * *}$} & {$[0.752]^{* *}$} & {$[0.736]^{* *}$} & {$[0.153]^{*}$} & {$[0.158]^{* *}$} & [0.152] \\
\hline \multirow[t]{2}{*}{ Pop. Density } & & 0.002 & & 0.009 & & & \\
\hline & & [0.013] & & {$[0.016]$} & & & \\
\hline \multirow[t]{2}{*}{ Urbanization } & & & -0.04 & -0.061 & & & \\
\hline & & & {$[0.063]$} & {$[0.075]$} & & & \\
\hline \multirow[t]{2}{*}{ Gold } & & & & & & & -0.411 \\
\hline & & & & & & & [0.000] \\
\hline \multirow[t]{2}{*}{ Iron } & & & & & & & 9.532 \\
\hline & & & & & & & {$[3,395.834]$} \\
\hline \multirow[t]{2}{*}{ Silver } & & & & & & & 2.544 \\
\hline & & & & & & & {$[1,567.478]$} \\
\hline \multirow[t]{2}{*}{ Zinc } & & & & & & & -5.762 \\
\hline & & & & & & & {$[2,667.827]$} \\
\hline \multirow[t]{2}{*}{ Aver. Temp. } & & & & & & 0.044 & \\
\hline & & & & & & {$[0.040]$} & \\
\hline \multirow[t]{2}{*}{ Latitude } & & & & & 0.048 & & \\
\hline & & & & & {$[1.492]$} & & \\
\hline \multirow[t]{2}{*}{ Constant } & 1.273 & 7.25 & 7.519 & 7.425 & 1.255 & 0.62 & 0.702 \\
\hline & {$[0.677]^{*}$} & {$[2.953]^{* *}$} & {$[3.217]^{* *}$} & {$[3.141]^{* *}$} & [0.881] & [0.890] & [0.770] \\
\hline Observations & 51 & 28 & 28 & 28 & 51 & 51 & 51 \\
\hline $\begin{array}{l}\text { Pseudo R- } \\
\text { squared }\end{array}$ & 0.07 & 0.44 & 0.45 & 0.46 & 0.07 & 0.09 & 0.19 \\
\hline \multicolumn{8}{|c|}{ Standard errors in brackets } \\
\hline \multicolumn{8}{|c|}{$*$ significant at $10 \% ; * *$ significant at $5 \% ; * * *$ significant at $1 \%$} \\
\hline
\end{tabular}


Table 22

\begin{tabular}{|c|c|c|c|c|c|c|c|}
\hline \multicolumn{8}{|c|}{ Common Law, Subsample 3: Marginal Effects } \\
\hline & 1 & II & III & IV & V & VI & VII \\
\hline \multirow[t]{2}{*}{ Mortality } & -0.118 & -0.724 & -0.716 & -0.708 & -0.117 & -0.149 & -0.011 \\
\hline & {$[0.055]^{* *}$} & {$[0.255]^{* * *}$} & {$[0.264]^{* * *}$} & {$[0.265]^{* * *}$} & {$[0.060]^{*}$} & {$[0.063]^{* *}$} & {$[17.566]$} \\
\hline \multirow[t]{2}{*}{ Pop. Density } & & 0.001 & & 0.004 & & & \\
\hline & & {$[0.005]$} & & {$[0.006]$} & & & \\
\hline \multirow[t]{2}{*}{ Gold } & & & & & & & -0.024 \\
\hline & & & & & & & [38.941] \\
\hline \multirow[t]{2}{*}{ Iron } & & & & & & & 0.562 \\
\hline & & & & & & & [742.189] \\
\hline \multirow[t]{2}{*}{ Silver } & & & & & & & 0.15 \\
\hline & & & & & & & [217.873] \\
\hline \multirow[t]{2}{*}{ Zinc } & & & & & & & -0.34 \\
\hline & & & & & & & [465.609] \\
\hline \multirow[t]{2}{*}{ Aver. Temp. } & & & & & & 0.018 & \\
\hline & & & & & & {$[0.016]$} & \\
\hline \multirow[t]{2}{*}{ Latitude } & & & & & 0.019 & & \\
\hline & & & & & [0.591] & & \\
\hline \multirow[t]{2}{*}{ Urbanization } & & & -0.016 & -0.024 & & & \\
\hline & & & {$[0.025]$} & [0.029] & & & \\
\hline Observations & 51 & 28 & 28 & 28 & 51 & 51 & 51 \\
\hline $\begin{array}{l}\text { Pseudo R- } \\
\text { squared }\end{array}$ & 0.07 & 0.44 & 0.45 & 0.46 & 0.07 & 0.09 & 0.19 \\
\hline \multicolumn{8}{|c|}{ Standard errors in brackets } \\
\hline \multicolumn{7}{|c|}{$*$ significant at $10 \% ; * *$ significant at $5 \% ; * * *$ significant at $1 \%$} & \\
\hline
\end{tabular}


Table 23

Multinomial Logit regression: the dependent variable is variable taking value 0 if England was the colonizer, 1 if France was the colonizer and 2 if Spain was.

\begin{tabular}{|c|c|c|c|c|c|c|}
\hline \multicolumn{7}{|c|}{ Multinomial Logit (England omitted): Coefficients } \\
\hline \multirow[b]{2}{*}{ Mortality } & 1 & II & III & IV & V & VI \\
\hline & 0.999 & 6.531 & 3.82 & 7.813 & 1.296 & 0.577 \\
\hline (France) & {$[0.340]^{* * *}$} & {$[1.739]^{* * *}$} & {$[1.769]^{* *}$} & {$[4.526]^{*}$} & {$[0.443]^{* * *}$} & {$[0.356]$} \\
\hline Mortality & 0.201 & 4.996 & 6.222 & 6.937 & 0.139 & 0.907 \\
\hline (Spain) & [0.297] & {$[2.533]^{* * *}$} & {$[2.402]^{* * *}$} & {$[2.708]^{* *}$} & [0.341] & {$[0.358]^{* *}$} \\
\hline Pop. Density & & -0.074 & & -6.445 & & \\
\hline (France) & & [0.107] & & {$[3.542]^{*}$} & & \\
\hline Pop. Density & & -0.945 & & -0.466 & & \\
\hline (Spain) & & {$[0.474]^{* *}$} & & [0.552] & & \\
\hline Urbanization & & & 0.14 & 1.502 & & \\
\hline (France) & & & [0.146] & {$[0.753]^{* *}$} & & \\
\hline Urbanization & & & -0.032 & 0.764 & & \\
\hline (Spain) & & & [0.100] & [0.578] & & \\
\hline Aver. Temp. & & & & & & 0.075 \\
\hline (France) & & & & & & [0.113] \\
\hline Aver. Temp. & & & & & & -0.213 \\
\hline \multicolumn{7}{|l|}{ (Spain) } \\
\hline Latitude & & & & & 5.123 & \\
\hline (France) & & & & & [3.642] & \\
\hline Latitude & & & & & -1.308 & \\
\hline (Spain) & & & & & [2.709] & \\
\hline Constant & -5.309 & -17.277 & -15.143 & -25.258 & -7.759 & -6.723 \\
\hline (France) & {$[1.697]^{* * *}$} & {$[6.773]^{* *}$} & {$[7.395]^{* *}$} & [21.745] & {$[2.699]^{* * *}$} & {$[2.829]^{* *}$} \\
\hline Constant & -1.304 & -27.326 & -28.355 & -35.741 & -0.785 & 1.606 \\
\hline (Spain) & [1.314] & {$[11.006]^{* *}$} & {$[10.807]^{* * *}$} & {$[9.889]^{* *}$} & [1.785] & [1.831] \\
\hline Observations & 56 & 36 & 36 & 36 & 56 & 56 \\
\hline $\begin{array}{l}\text { Pseudo R- } \\
\text { squared }\end{array}$ & 0.1 & 0.62 & 0.35 & 0.8 & 0.13 & 0.2 \\
\hline Standard erro & in brackets & & & & & \\
\hline
\end{tabular}

Notice that measures of natural resources have been removed. They were not significant. 
Table 24

Multinomial Logit (England omitted): Marginal Effect

\begin{tabular}{|c|c|c|c|c|c|c|}
\hline & 1 & II & III & IV & V & VI \\
\hline Mortality & 0.16 & 0.881 & 0.83 & 0.502 & 0.209 & 0.062 \\
\hline (France) & {$[0.052]^{* * *}$} & {$[0.504]^{*}$} & [0.128] & [0.826] & [0.065] & {$[0.057]^{* *}$} \\
\hline Mortality & -0.027 & 0.073 & 0.172 & 0 & -0.057 & 0.117 \\
\hline (Spain) & {$[0.056]$} & [0.183] & {$[0.445]^{*}$} & {$[0.000]$} & {$[0.066]^{* * *}$} & {$[0.067]$} \\
\hline Pop. Density & & -0.007 & & 0 & & \\
\hline (France) & & [0.018] & & [0.000] & & \\
\hline Pop. Density & & -0.017 & & -0.03 & & \\
\hline (Spain) & & [0.037] & & {$[0.070]$} & & \\
\hline Urbanization & & & 0.006 & 0 & & \\
\hline (France) & & & [0.005] & [0.094] & & \\
\hline Urbanization & & & -0.011 & 0.049 & & \\
\hline (Spain) & & & {$[0.024]$} & {$[0.000]$} & & \\
\hline Aver. Temp. & & & & & & 0.026 \\
\hline (France) & & & & & & [0.016] \\
\hline Aver. Temp. & & & & & & -0.048 \\
\hline \multicolumn{7}{|l|}{ (Spain) } \\
\hline Latitude & & & & & 0.949 & \\
\hline (France) & & & & & {$[0.566]^{*}$} & \\
\hline Latitude & & & & & -0.627 & \\
\hline (Spain) & & & & & [0.561] & \\
\hline Observations & 56 & 36 & 36 & 36 & 56 & 56 \\
\hline $\begin{array}{l}\text { Pseudo R- } \\
\text { squared }\end{array}$ & 0.1 & 0.62 & 0.35 & 0.8 & 0.13 & 0.2 \\
\hline \multicolumn{7}{|c|}{ Standard errors in brackets } \\
\hline * significant a & ; ** significar & at $5 \% ; * *$ & ignificant & t $1 \%$ & & \\
\hline
\end{tabular}

Notice that measures of natural resources have been removed. They were not significant. 
Table 25

Probit regression: the dependent variable is dummy indicating whether the colonizer was a protestant country.

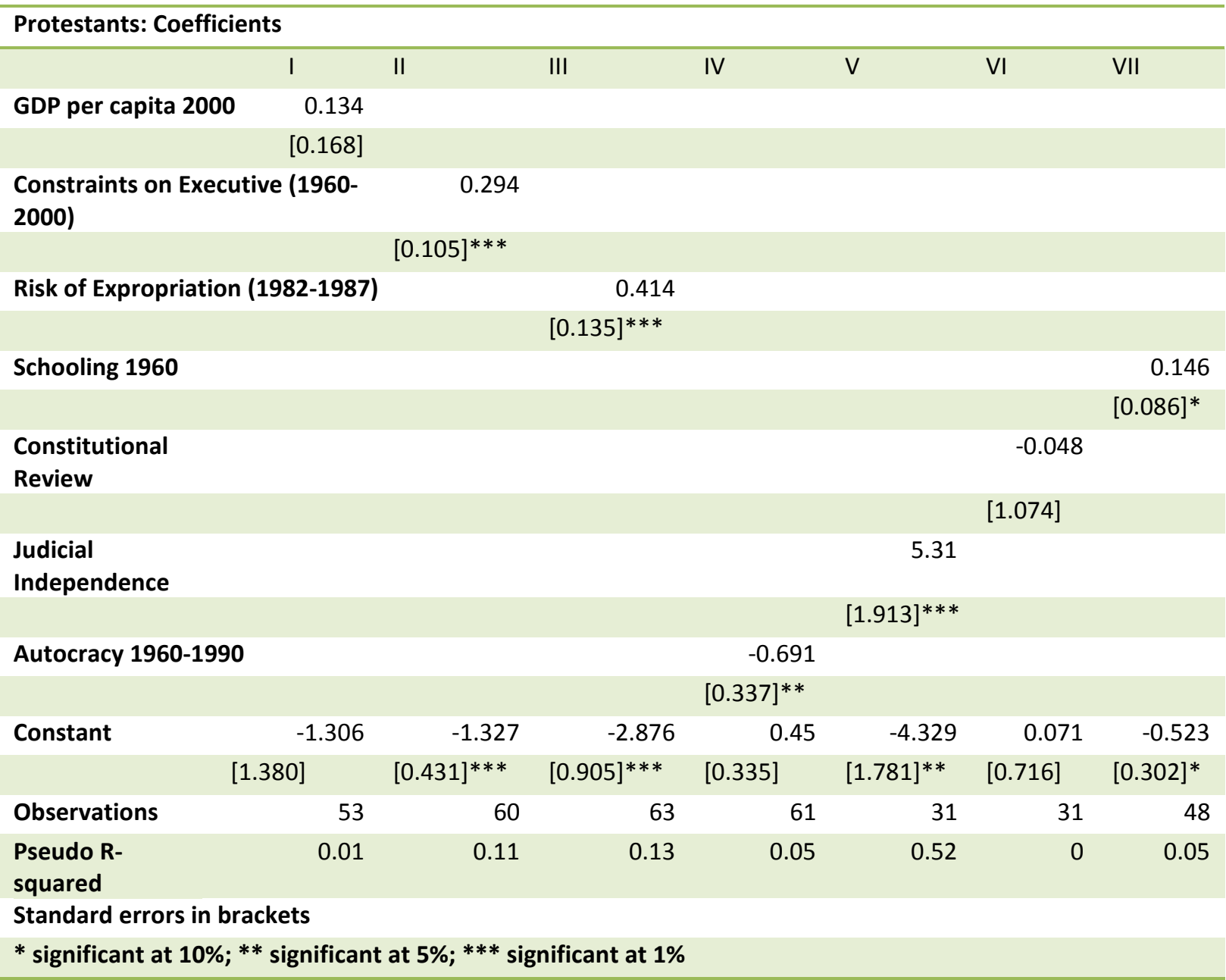


Table 26

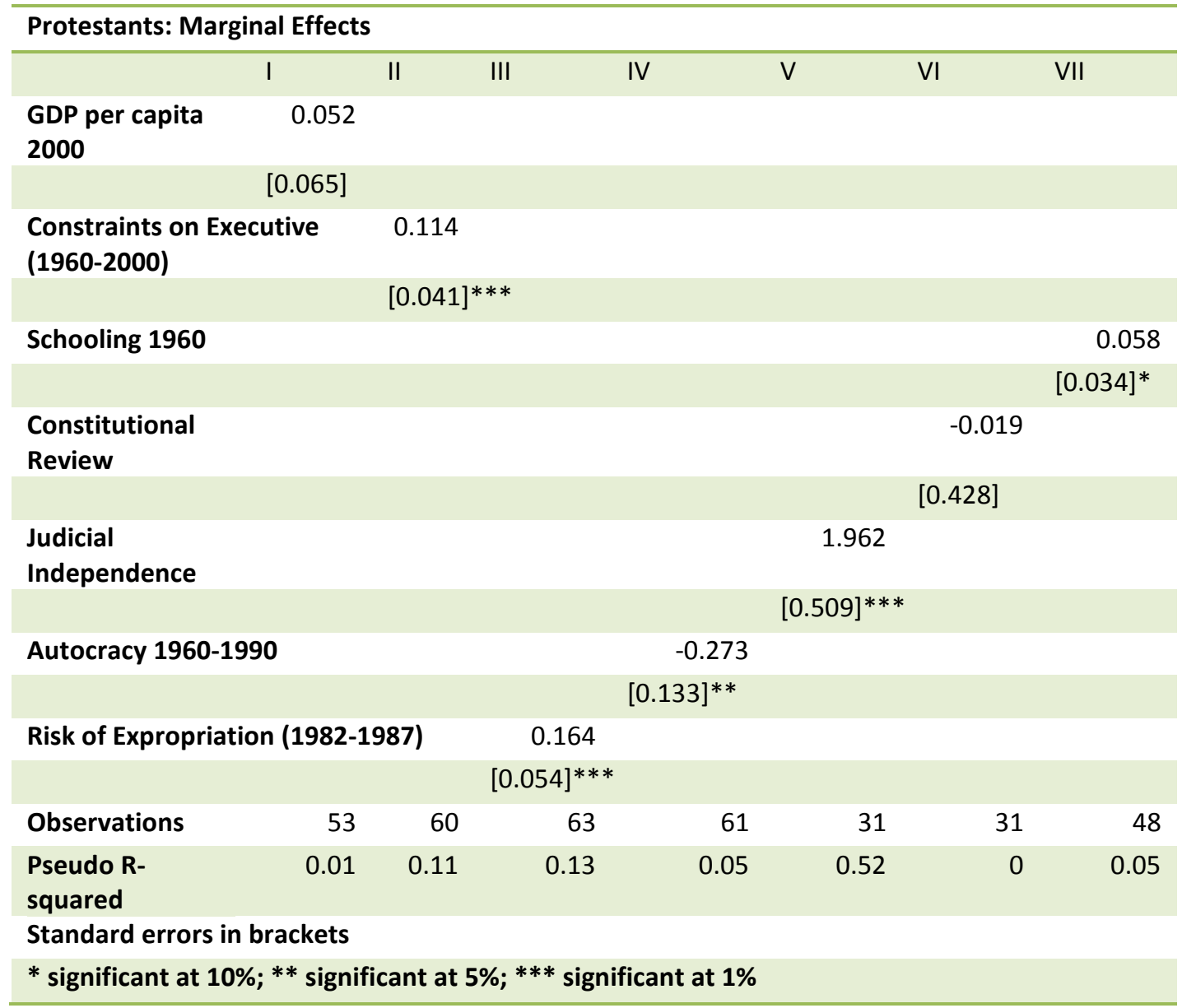


Table 27

Probit regression: the dependent variable is dummy indicating whether the colonizer was England.

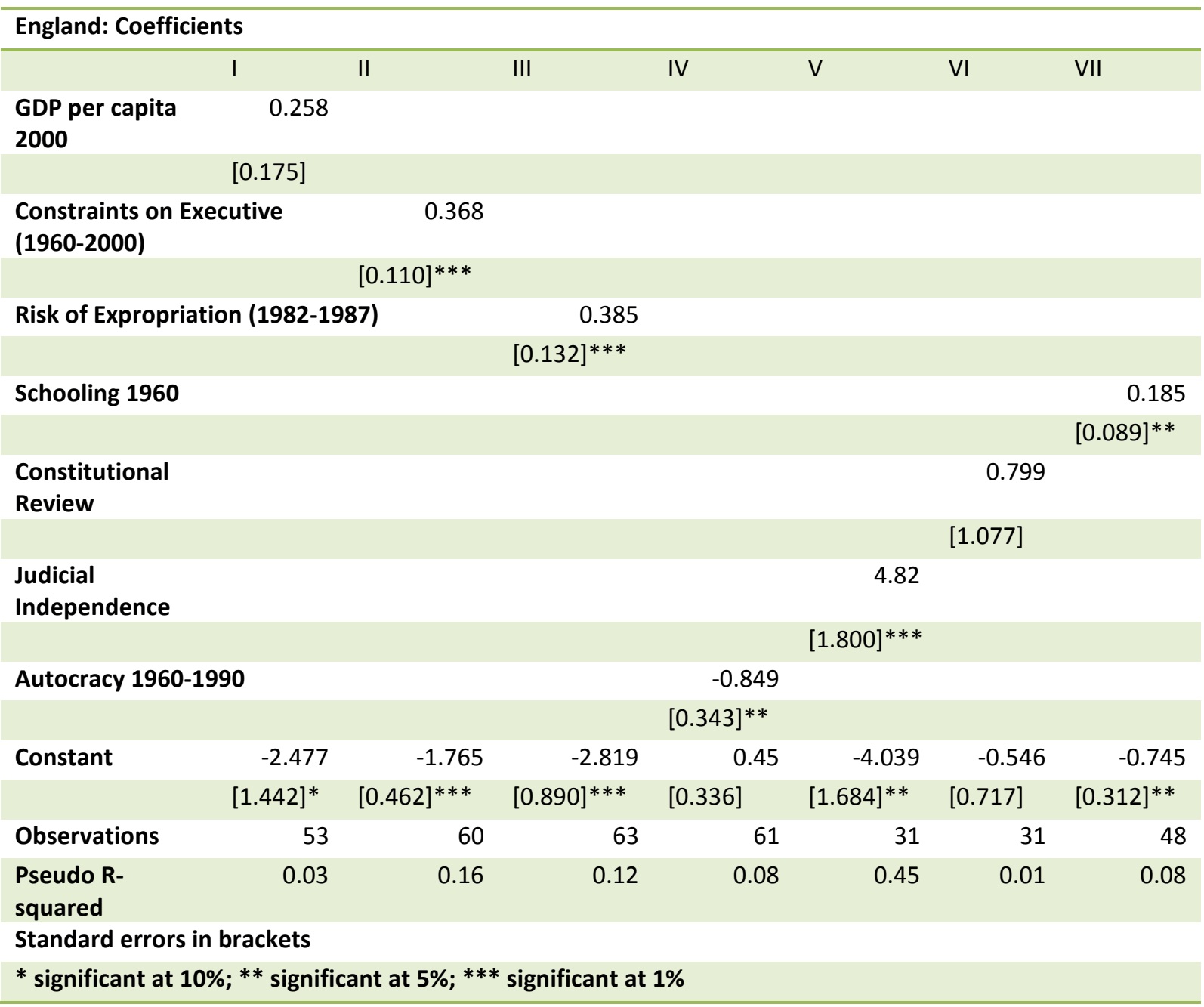


Table 28

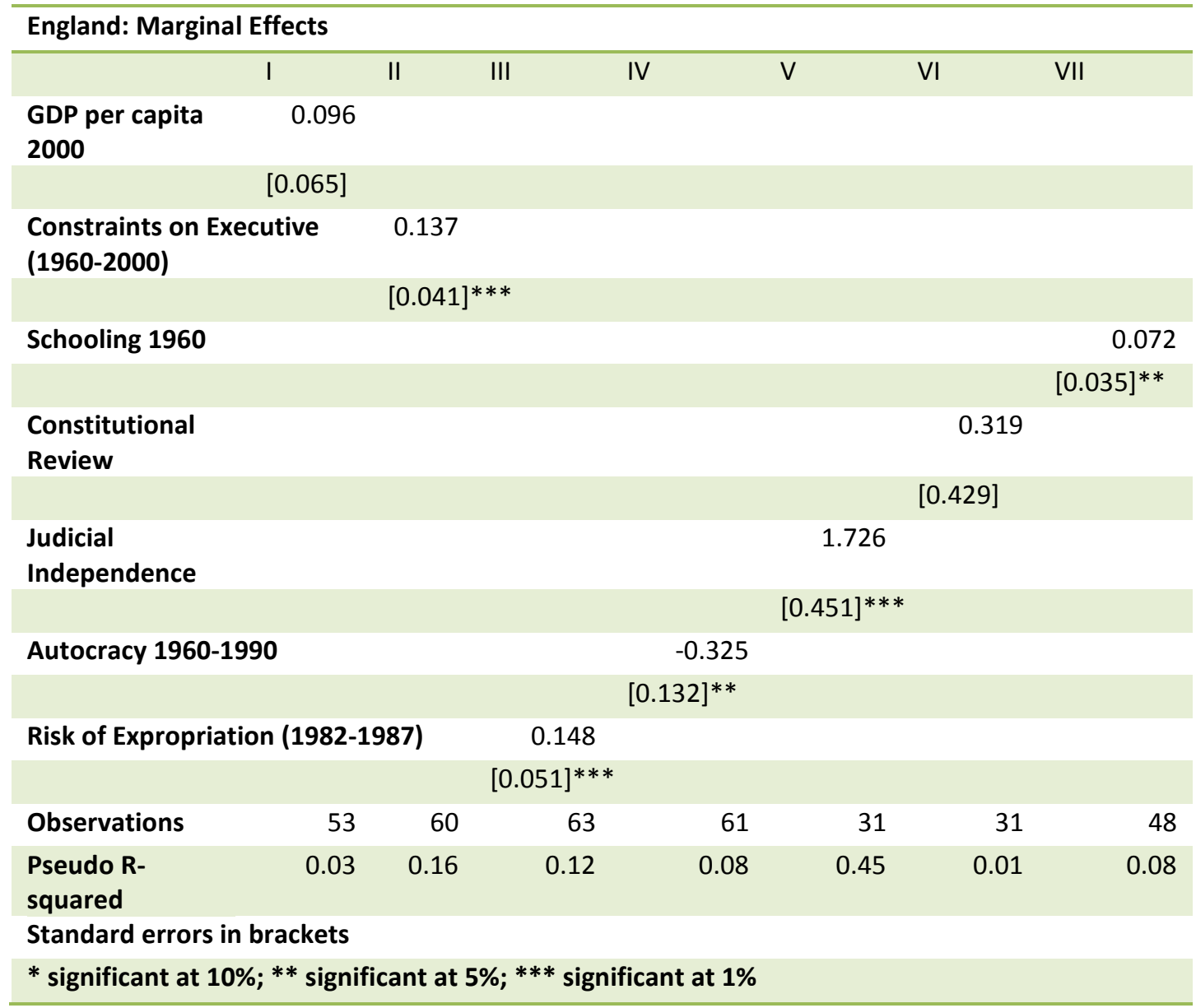


Table 29

Probit regression: the dependent variable is dummy indicating whether the colonizer was France.

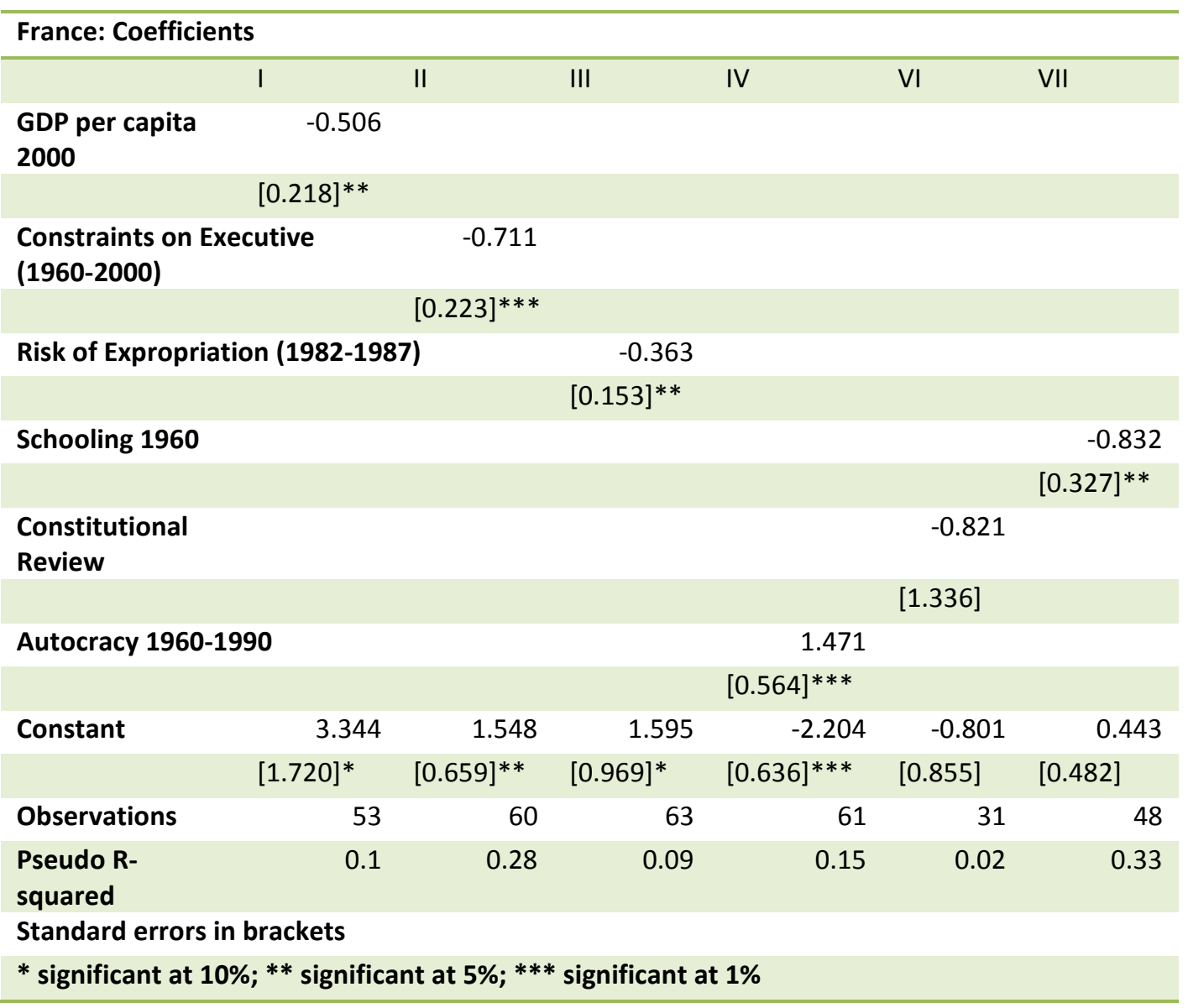

Note: judicial independence perfectly predicts failure below 0.33 
Table 30.

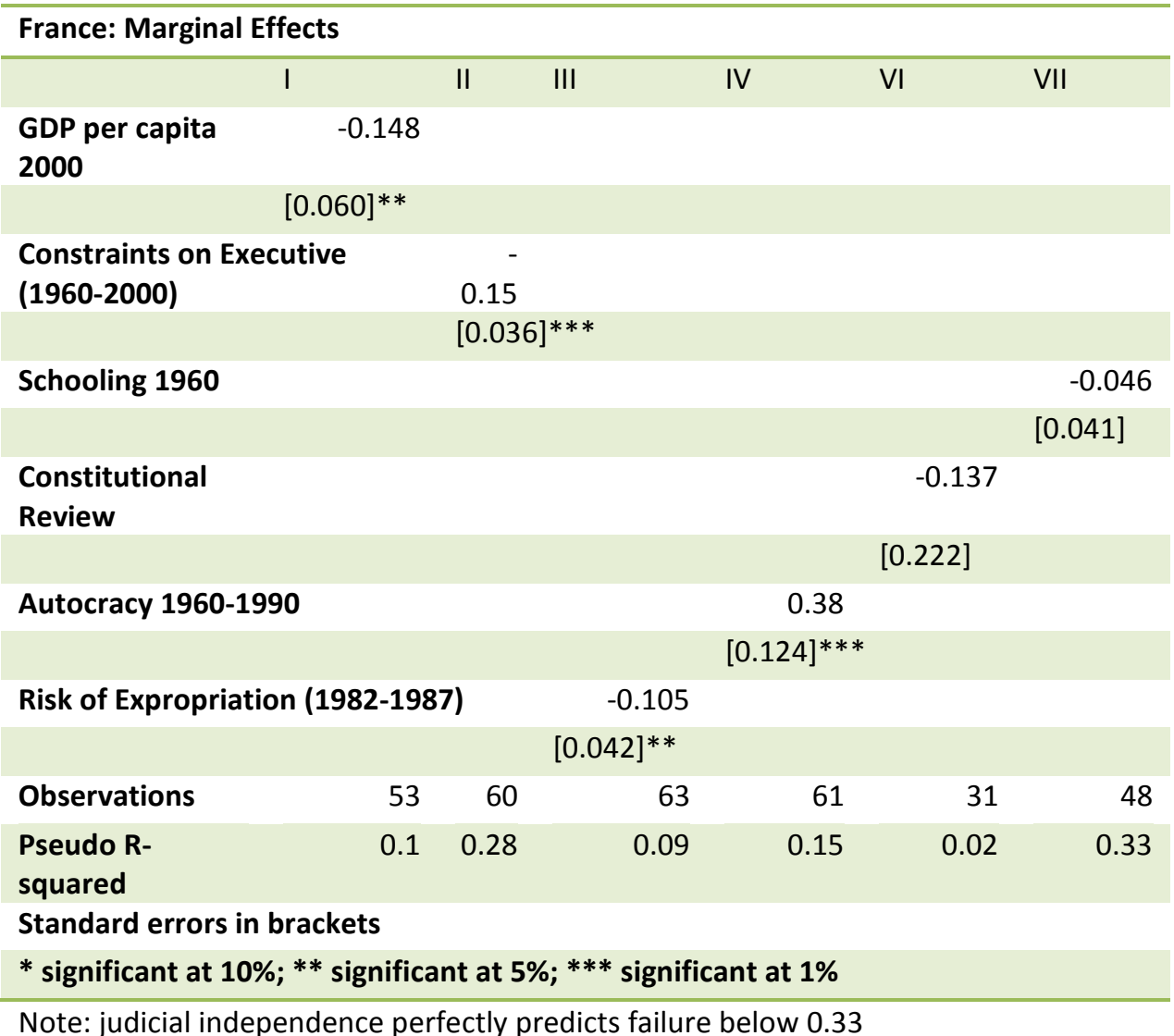


Table 31

Probit regression: the dependent variable is dummy indicating whether the colonizer was Spain.

\begin{tabular}{|c|c|c|c|c|c|c|c|}
\hline \multicolumn{8}{|l|}{ Spain: Coefficients } \\
\hline & 1 & II & III & IV & V & VI & VII \\
\hline \multirow{2}{*}{$\begin{array}{l}\text { GDP per capita } \\
2000\end{array}$} & 0.31 & & & & & & \\
\hline & {$[0.186]^{*}$} & & & & & & \\
\hline \multirow{2}{*}{\multicolumn{2}{|c|}{$\begin{array}{l}\text { Constraints on Executive } \\
(1960-2000)\end{array}$}} & 0136 & & & & & \\
\hline & & 0.136 & & & & & \\
\hline & & [0.102] & & & & & \\
\hline \multicolumn{3}{|c|}{ Risk of Expropriation (1982-1987) } & -0.09 & & & & \\
\hline & & & {$[0.130]$} & & & & \\
\hline \multirow[t]{2}{*}{ Schooling 1960} & & & & & & & 0.052 \\
\hline & & & & & & & {$[0.080]$} \\
\hline \multirow{3}{*}{$\begin{array}{l}\text { Constitutional } \\
\text { Review }\end{array}$} & & & & & & 0.616 & \\
\hline & & & & & & & \\
\hline & & & & & & [1.217] & \\
\hline \multirow{2}{*}{$\begin{array}{l}\text { Judicial } \\
\text { Independence }\end{array}$} & & & & & -1.381 & & \\
\hline & & & & & {$[0.692]^{* *}$} & & \\
\hline \multirow[t]{2}{*}{ Autocracy 1960-199 } & & & & -0.375 & & & \\
\hline & & & & {$[0.352]$} & & & \\
\hline \multirow[t]{2}{*}{ Constant } & -3.085 & -1.156 & -0.075 & -0.325 & 0.515 & -0.855 & -0.586 \\
\hline & {$[1.562]^{* *}$} & {$[0.444]^{* * *}$} & {$[0.863]$} & {$[0.336]$} & {$[0.537]$} & {$[0.821]$} & {$[0.309]^{*}$} \\
\hline Observations & 53 & 60 & 63 & 61 & 31 & 31 & 48 \\
\hline $\begin{array}{l}\text { Pseudo R- } \\
\text { squared }\end{array}$ & 0.04 & 0.03 & 0.01 & 0.02 & 0.1 & 0.01 & 0.01 \\
\hline \multicolumn{8}{|c|}{ Standard errors in brackets } \\
\hline \multicolumn{8}{|c|}{$*$ significant at $10 \% ; * *$ significant at $5 \% ; * * *$ significant at $1 \%$} \\
\hline
\end{tabular}


Table 32

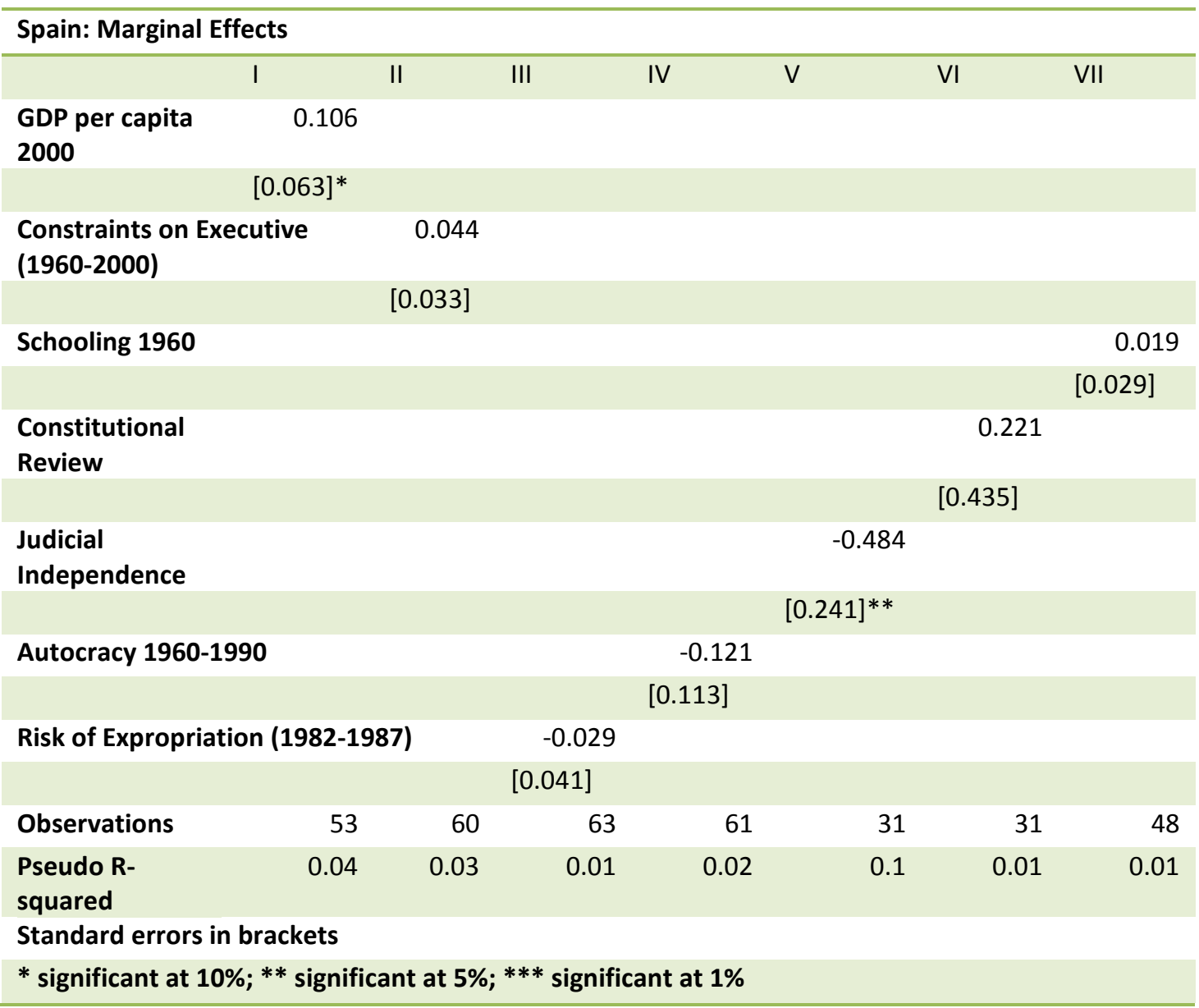

